\title{
Article \\ Optimization of the Configuration and Operating States of Hybrid AC/DC Low Voltage Microgrid Using a Clonal Selection Algorithm with a Modified Hypermutation Operator
}

\author{
Łukasz Rokicki
}

check for updates

Citation: Rokicki, Ł. Optimization of the Configuration and Operating States of Hybrid AC/DC Low Voltage Microgrid Using a Clonal Selection Algorithm with a Modified Hypermutation Operator. Energies 2021, 14, 6351. https://doi.org/ $10.3390 /$ en14196351

\section{Academic Editors: Luis}

Hernández-Callejo and Ricardo J. Bessa

Received: 11 August 2021

Accepted: 27 September 2021

Published: 5 October 2021

Publisher's Note: MDPI stays neutral with regard to jurisdictional claims in published maps and institutional affiliations.

Copyright: (C) 2021 by the author Licensee MDPI, Basel, Switzerland. This article is an open access article distributed under the terms and conditions of the Creative Commons Attribution (CC BY) license (https:/ / creativecommons.org/licenses/by/ $4.0 /)$.
Faculty of Electrical Engineering, Warsaw University of Technology, Koszykowa 75 Street, 00-662 Warsaw, Poland; lukasz.rokicki@pw.edu.pl; Tel.: +48-22-234-7951

\begin{abstract}
The issue of optimization of the configuration and operating states in low voltage microgrids is important both from the point of view of the proper operation of the microgrid and its impact on the medium voltage distribution network to which such microgrid is connected. Suboptimal microgrid configuration may cause problems in networks managed by distribution system operators, as well as for electricity consumers and owners of microsources and energy storage systems connected to the microgrid. Structures particularly sensitive to incorrect determination of the operating states of individual devices are hybrid microgrids that combine an alternating current and direct current networks with the use of a bidirectional power electronic converter. An analysis of available literature shows that evolutionary and swarm optimization algorithms are the most frequently chosen for the optimization of power systems. The research presented in this article concerns the assessment of the possibilities of using artificial immune systems, operating on the basis of the CLONALG algorithm, as tools enabling the effective optimization of low voltage hybrid microgrids. In his research, the author developed a model of a hybrid low voltage microgrid, formulated three optimization tasks, and implemented an algorithm for solving the formulated tasks based on an artificial immune system using the CLONALG algorithm. The conducted research consisted of performing a $24 \mathrm{~h}$ simulation of microgrid operation for each of the formulated optimization tasks (divided into 10 min independent optimization periods). A novelty in the conducted research was the modification of the hypermutation operator, which is the key mechanism for the functioning of the CLONALG algorithm. In order to verify the changes introduced in the CLONALG algorithm and to assess the effectiveness of the artificial immune system in solving optimization tasks, optimization was also carried out with the use of an evolutionary algorithm, commonly used in solving such tasks. Based on the analysis of the obtained results of optimization calculations, it can be concluded that the artificial immune system proposed in this article, operating on the basis of the CLONALG algorithm with a modified hypermutation operator, in most of the analyzed cases obtained better results than the evolutionary algorithm. In several cases, both algorithms obtained identical results, which also proves that the CLONALG algorithm can be considered as an effective tool for optimizing modern power structures, such as low voltage microgrids, including hybrid AC/DC microgrids.
\end{abstract}

Keywords: hybrid AC/DC microgrid; optimization of configuration and operating states; CLONALG; modified hypermutation operator

\section{Introduction}

Over the last few years, the development of distributed, renewable energy sources (RES) and growing interest in prosumer installations have been observed. The presence of a large number of generation sources and energy storage devices (ESDs) in low voltage distribution networks promotes the creation of microgrids which are capable of synchronous operation with the remaining part of the power system as well as autonomous island operation. 
A significant part of the ESDs and microsources used in microgrids generate DC voltage. Connecting them to the $\mathrm{AC}$ network requires the use of $\mathrm{DC} / \mathrm{AC}$ electronic power converters (EPCs). Some AC microsources, due to the high voltage frequency, require a connection to the microgrid via AC/AC converters. The use of EPCs between microsource or energy storage device and the AC network results in additional power losses and reduces the efficiency of generation units. Increasing the efficiency of the devices included in the microgrid is possible by connecting energy sources and storage devices generating DC voltage to the $\mathrm{DC}$ network and units generating $\mathrm{AC}$ voltage to the $\mathrm{AC}$ network. Both types of network can be connected with each other by means of a single, bidirectional AC/DC converter, thus creating a low voltage hybrid microgrid.

The complexity of a low voltage microgrid, resulting from a large number of microsources, ESDs, EPCs, and controlled loads, requires the development of an appropriate management system for their operation in order to achieve maximum efficiency of RES. Proper selection of elements forming the microgrid, as well as subsequent determination of the operating states of individual devices in such a way that the microgrid as a whole is in the optimal configuration for the problem under consideration is not an easy task. The complexity of the calculations is directly proportional to the number of devices installed. The creation of an effective control system is possible by using appropriate optimization algorithms, including those that use artificial intelligence methods. The division of optimization algorithms that can be used in problems related to microgrids is shown in Figure 1.

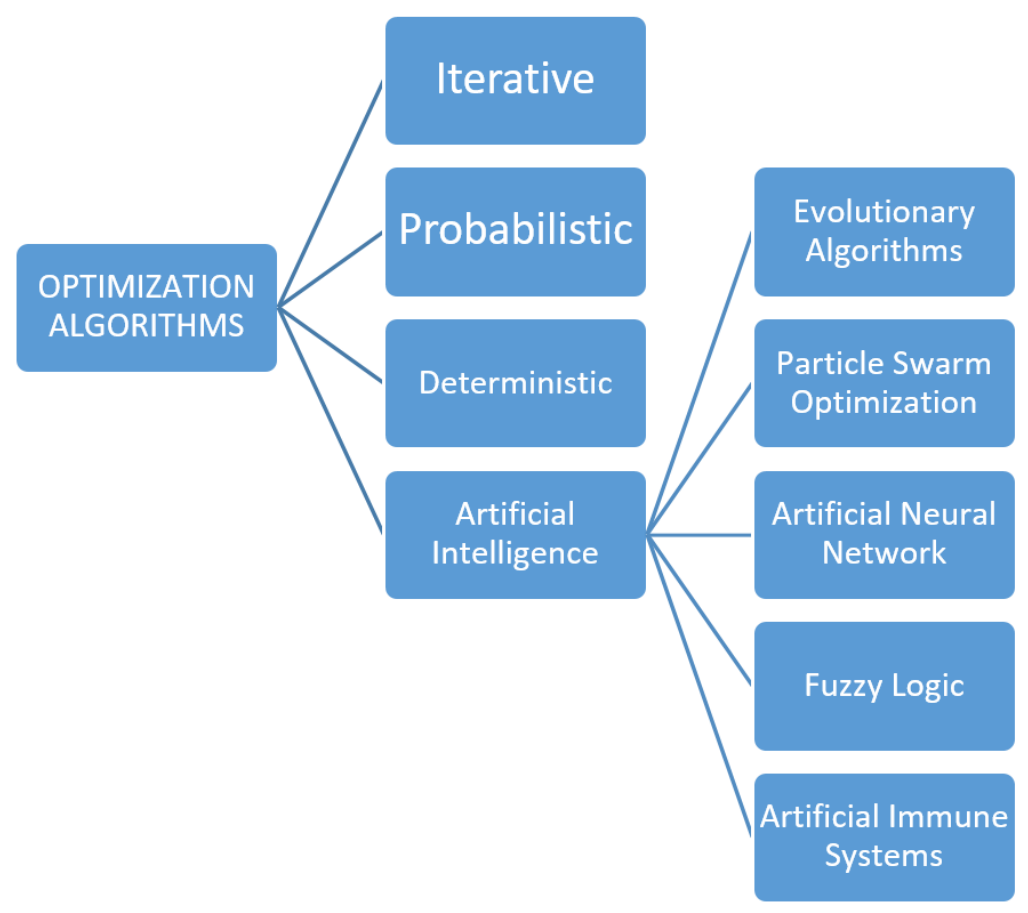

Figure 1. Division of optimization algorithms.

Among the methods of artificial intelligence used in solving optimization tasks, the most popular are evolutionary algorithms (EA) and particle swarm optimization (PSO). In article [1], a memory-based genetic algorithm, which is a type of EA, was used to minimize the power generation costs in the smart grid framework. The proposed method shares optimal power generation in a microgrid through different types of microsources. The authors of [2] use differential evolution algorithm (type of EA) for optimal single-objective economic scheduling and bi-objective environmental-economic scheduling of community microgrids. Another popular artificial intelligence method used to solve optimization tasks is the PSO algorithm. In paper [3], PSO was used to find economically optimal solutions for day-ahead scheduling strategy of a microgrid equipped with CHP microsources. Article [4] 
concerns the use of the PSO as a management system of microgrids composed of different types of microsources and energy storage devices to minimize total operating costs of the microgrid.

There are many other artificial intelligence methods that can be used for solving different optimizations tasks, such as Artificial Neural Network, Fuzzy Logic or Artificial Immune Systems (AIS) [5-7]. The main objective of the research presented in this paper is to assess whether the AIS, operating on the basis of the CLONALG algorithm, can be used as an effective tool for optimizing the configuration and operating states of low voltage AC/DC hybrid microgrids.

\subsection{Review of Knowledge in the Field of Hybrid AC/DC Microgrids}

The article [8] presents an overview of microgrids cooperating with AC and DC power grids. Advantages and disadvantages of both technologies were discussed in detail in this publication. The differences in the manner of connecting microsources, ESDs, and receivers to the networks were described, and schematic diagrams of EPCs, protection, and monitoring systems were presented. The article also contains an overview of control and optimization systems aimed at ensuring the quality of electricity and stability of the microgrid. The publication was completed with an economic analysis and examples of operating microgrids all over the world.

Hybrid AC/DC systems constitute a separate group of microgrids. An outline of the structure of hybrid microgrid was presented in [9] and the first research works began in 2010 [10]. The simplest hybrid microgrid is composed of AC and DC networks connected to each other by means of a bidirectional AC/DC EPC [11-14]. In paper [15], the planning process of a hybrid AC/DC microgrid with optimal placement of DC feeders was described. The concept, control paradigm, and implementation of a bus-sectionalized hybrid microgrid was presented in article [16].

Both AC and DC networks in a hybrid microgrid have the same types of microsources and ESDs. The coexistence of AC and DC networks allows for greater efficiency of installed devices than in case of solutions using only one type of voltage. The DC network of the hybrid microgrid is a natural place for connecting photovoltaic panels [17,18], fuel cells [19], wind turbine generation sets equipped with DC generators [19], battery energy storage systems [20], and supercapacitors. The ability to integrate AC and DC networks within a hybrid microgrid can also contribute to the development of V2G technology [21-23].

Creating a hybrid microgrid concept allows combining the advantages of DC and AC networks, as well as eliminating some of the disadvantages of these network. The main advantages of using hybrid microgrids are described in [24] and include:

- reduction of energy conversion levels in EPCs and associated power losses,

- increasing the efficiency of RES,

- increasing the level of reliability of energy supply,

- increasing flexibility in regulatory services,

- limiting the impact of higher current and voltage harmonics,

- the ability to simplify the design of some electricity consumers by not having to use a built-in EPCs.

In terms of the method of connecting the hybrid microgrid to the external distribution network, coupled and separated topologies can be distinguished. In coupled topologies, the distribution network and the AC network of the hybrid microgrid are connected directly to each other using an MV / LV transformer. The DC network is connected using a two-way AC/DC converter. This converter can be connected to both low voltage and medium voltage sides of the transformer. In the case of separated topologies, the microgrid DC network is connected to the distribution grid through an AC/DC converter. Depending on the design, this converter can be connected directly to the medium voltage network or using a step-down transformer. In both of these cases, the AC low voltage network does not have a direct connection to the distribution grid. A detailed description of coupled and separated topologies is provided in [25]. 
As with other types of microgrids, popularization of hybrid microgrids requires the development of appropriate solutions for protection systems, taking into account the specificity of AC and DC networks. Detailed methods for solving problems related to the protection of hybrid microgrids are presented in publications [26-28].

In the field of architecture of hybrid microgrid control systems, the same centralized and distributed control solutions are used as in the case of AC and DC microgrids. It should be noted that the hybrid microgrid control system must provide the ability to control the operating states of the AC/DC converter connecting the networks of both types of voltage in order to properly manage energy exchange between them. An example of a hybrid microgrid centralized control system has been described in [29]. Article [30] presents a coordination control strategy for a hybrid microgrid in standalone mode.

\subsection{Objective and Contribution}

The main objective of this paper is the assessment of the effectiveness of the AIS in solving tasks related to the optimization of the configuration and operating states of a hybrid AC/DC low voltage microgrid. Below are the contributions of this paper:

- modification of hypermutation operator used in the CLONALG algorithm,

- development of an optimization algorithm of operating states of hybrid AC/DC low voltage microgrid,

- comparison of the obtained results using classic and modified CLONALG algorithms as well as evolutionary algorithms.

The remainder of this paper is organized as follows: Section 2.1 presents the formulated optimization tasks. The mathematical models of this tasks are presented in Section 2.2. Section 3 describes the proposed microgrid optimization algorithm. The case study, including description of the test hybrid AC/DC low voltage microgrid, results of optimization calculations, as well as comparison of the calculation results obtained using the CLONALG algorithm and the evolutionary algorithm and discussion about these results are presented in Section 4. The summary and main conclusions are included in Section 5. The paper ends with a list of references.

\section{Optimization Problem Formulation}

In order to ensure proper operation of the hybrid AC/DC microgrid as a coherent system, it is necessary to implement appropriate strategies for controlling the operation of individual components of this system. The strategy of centralized two-stage control is considered in this article. Each of the microsources, ESDs, EPCs, and controlled loads should be equipped with a local controller. The task of local controllers is to collect information about the status of individual devices and send them to a central controller, which carries out the process of optimal control of the microgrid. Local controllers also receive signals from the central controller and force the appropriate behavior of the devices they control. The adopted control strategy allows the hybrid microgrid to operate in a synchronous mode with an external distribution grid, or autonomously in island mode. In both of these cases, determining the operating states is necessary to meet the given optimization criteria. The central controller must also distinguish between a number of factors affecting the possible operating states of microgrid components, such as power demand values and generation capacities of RES during the optimization period, acceptable regulatory ranges of individual devices in microgrid, instantaneous energy storage state of charge (SOC) levels, technical data of microgrid components, and mode of microgrid cooperation with an external distribution grid.

\subsection{Optimization Tasks}

In this paper, three single-criteria optimization tasks are formulated:

- task 1-minimization of total active power losses,

- task 2-minimization of costs associated with the operation of the hybrid AC/DC microgrid, 
- $\quad$ task 3-maximization of level of power generated by RES.

In the first task, the control strategy assumes that the individual devices included in a hybrid microsystem will be controlled to obtain the lowest possible values of total active power losses in the optimization period under consideration. The amount of this losses can be described by the following formula:

$$
\Delta P_{T O T_{T}}=\sum_{i=1}^{N_{l}} \Delta P_{l_{i}}+\sum_{j=1}^{N_{T R}} \Delta P_{T R_{j}}+\sum_{k=1}^{N_{E P C}} \Delta P_{E P C_{k}}
$$

The reduction of active power losses is achieved by changing the power flow in the microgrid, resulting from the levels of microsources generation, load level and mode of operation of ESDs, as well as the demand for controlled loads. To minimize active power losses, microgrid central controller must have information about the current power flow in the microgrid and determine the expected power flow for subsequent settings of individual microgrid elements.

In the second task, control strategy assumes determination of such operating states of individual components of hybrid microgrid so that the total costs related to the functioning of this microgrid in the considered optimization period will be as low as possible. In order to implement this strategy, a hybrid microgrid operator (HMO) was defined as an intermediary in financial settlements between customers and the distribution system operator $(D S O)$. The costs to be minimized can be written using the following formulas:

$$
\begin{gathered}
C_{T_{O O T_{T}}}=C_{F I X_{T}}+C_{V A R_{T}} \\
C_{F I X_{T}}=C_{F I X_{D S O}}+C_{F I X_{M S H M O}}+C_{F I X_{E S H M O}}+C_{F I X_{M E L}} \\
C_{V A R_{T}}=C_{V A R_{D S O}}+C_{V A R_{M S H M O}}+C_{V A R_{M S L}}+C_{V A R_{E S H M O}}+C_{V A R_{E S L}}
\end{gathered}
$$

In the last task, the control strategy consists of determining the operating states of individual components of the hybrid microgrid so that the sum of power generated in microsources using renewable primary energy resources is as high as possible in the considered optimization period. The level of power generated by RES is determined by the following formula:

$$
P_{R E S_{T}}=\sum_{i=1}^{N_{R E S}} P_{G_{i}}
$$

\subsection{Mathematical Models of Formulated Optimization Tasks}

In order to solve formulated optimization tasks, appropriate mathematical models are defined for each of them, containing a problem representation, the form of objective function, and a set of constraints.

For each of the formulated tasks, a $\delta$ vector is defined, which represents a set of solutions to a given optimization problem. This vector contains a binary sequence coding the operating states of individual components of the hybrid microgrid. On the basis of the data contained in the $\delta$ vector, load flow calculations on the hybrid microgrid are performed, and then, depending on the considered optimization criterion, the following are determined: active power losses, costs related to the operation of the hybrid microgrid and RES generation levels. The mathematical notation of the objective functions defined for individual tasks is as follows:

$$
\begin{gathered}
F_{O_{1}}=\min _{\delta}\left\{\Delta P_{T_{O O T}}(\delta)\right\} \\
F_{O_{2}}=\min _{\delta}\left\{C_{T O T_{T}}(\delta)\right\} \\
F_{O_{3}}=\max _{\delta}\left\{P_{R E S_{T}}(\delta)\right\}
\end{gathered}
$$


Determining the optimal operating states of a hybrid microgrid requires that the following constraints be met:

- $\quad$ none of the microsources/ESDs connected the hybrid microgrid may operate with output power greater than nominal power of this microsource/ESD:

$$
\begin{aligned}
S_{i} & \leq S_{n_{i}} \forall i \in M S_{A C} \\
P_{i} & \leq P_{n_{i}} \forall i \in M S_{D C} \\
S_{E S D_{A C_{i}}} & \leq S_{E S D_{A C n_{i}}} \forall i \in S D_{A C} \\
P_{E S D_{D C_{i}}} & \leq P_{E S D_{D C n_{i}}} \forall i \in S D_{D C}
\end{aligned}
$$

- none of the microsources/ESDs/EPCs connected to the AC part of hybrid microgrid may operate with a power factor $\cos (\varphi)$ lower than the nominal power factor of this microsource/ESD/EPC:

$$
\begin{gathered}
\cos \varphi_{M S_{i}} \geq \cos \varphi_{M S_{n_{i}}} \forall i \in M S_{A C} \\
\cos \varphi_{E S D_{i}} \geq \cos \varphi_{E S D_{n_{i}}} \forall i \in S D_{A C} \\
\cos \varphi_{E P C_{i}} \geq \cos \varphi_{E P C_{n_{i}}} \forall i \in P C
\end{gathered}
$$

- current flow in any of the power lines should not be greater than the long-term current carrying capacity of this power line:

$$
I_{i} \leq I_{\mathcal{C C}_{i}} \forall i \in L
$$

- voltage level at each of the hybrid microgrid nodes may not exceed the maximum or minimum allowable values:

$$
U_{\text {min }_{i}} \leq U_{i} \leq U_{\text {max }_{i}} \forall i \in N
$$

- $\quad$ power flow in the EPC/transformer cannot be greater than the nominal power of this $E P C /$ transformer:

$$
\begin{gathered}
S_{E P C_{A C_{i}}} \leq S_{E P C_{n i}} \forall i \in P C \\
P_{E P C_{D C_{i}}} \leq P_{E P C_{n i}} \forall i \in P C \\
S_{T R_{i}} \leq S_{T R_{n i}} \forall i \in T R
\end{gathered}
$$

- The SOC level of each ESD should be within the limits allowed for that ESD:

$$
S O C_{\min _{i}} \leq S O C_{i} \leq S O C_{\text {max }_{i}} \forall i \in S D
$$

- the synchronous generator acting as a balancing source in the AC part of the hybrid microgrid cannot go into motor operation:

$$
P_{S G} \geq 0
$$

\section{Description of the Proposed Microgrid Optimization Algorithm}

An AIS based on a CLONALG will be used to solve the defined optimization tasks. In order to "build" a properly functioning immune system, it is necessary to determine:

- the method of representation of the optimization task solutions,

- how to create the initial set of antibodies (candidate solutions), 
- the method of assessing the solution (formulation of the evaluation function),

- how to adapt the AIS during its operation.

A binary representation of the problem is assumed for each of the defined optimization tasks. The antibody should then be understood as the $\delta$ vector encoding the operating states of all devices controlled by the immune system within a hybrid microgrid. The $\delta$ vector consists of a binary sequence divided into groups of different lengths, coding individual operating states. The number of groups is equal to the number of operating states determined during the operation of AIS. Determining the number of bits belonging to a single group (length of a group) requires knowledge of the allowable adjustment range of individual devices and the expected accuracy (number of decimal digits).

The initial set of antibodies is created as a $N \times l$ matrix, where $N$ is the number of antibodies in the set and $l$ is the number of bits encoding the given antibody-size of the antibody. Knowing the number of antibodies and their size, the optimization algorithm randomly assigns the values " 0 " or " 1 " to individual bits, creating the initial set of antibodies.

After creating the initial set of antibodies, an optimization algorithm determines the operating states of individual devices installed in the microgrid. The next steps performed by the algorithm are the calculation of the power flow, determining the value of the evaluation function appropriate for the optimization task being solved.

The transformation of the objective functions defined in Section 3 into evaluation functions is necessary due to the development of a universal algorithm for solving minimizing and maximizing optimization tasks. In the case of minimizing tasks, the objective and evaluation functions are identical. For the maximization task 3 evaluation function take the following form:

$$
\mathrm{eval}_{3}=\mathrm{C}_{3}-F_{0_{3}}
$$

Formulation of the evaluation functions in accordance with the above-mentioned description aims at transforming all defined optimization tasks into minimizing tasks.

The load flow calculation performed by the optimization algorithm also allows to check whether the found solution does not violate the constraints. The algorithm enforces compliance with constraints by introducing appropriate penalty functions whose task is to increase the value of evaluation function in case of violation of constraints. The general mathematical notation of penalty functions is as follows:

$$
\begin{gathered}
\text { eval }_{p_{i}}=\text { eval }_{i} \cdot \prod_{j=1}^{n} \Psi_{j} \\
\Psi_{j}= \begin{cases}1 & \text { in the absence of violations } \\
a_{j}+\psi_{j} b_{j} & \text { if violations occur }\end{cases}
\end{gathered}
$$

The operation of the AIS is based on determining the affinity of the antibody to the presented antigen, whose role in optimization tasks is performed by the antibody encoding the best solution found so far for the given task. The determination of affinity is calculated as follows:

$$
A F F_{i}=\frac{\text { best_eval }}{\text { eval } p_{i}}
$$

After determining the affinity, antibodies in the set are sorted in descending order. The next step performed by the algorithm is to select $N 1$ antibodies with the highest affinity and create their clones. The number of clones is directly proportional to the affinity of the antibody and calculated as follows:

$$
N_{C L_{i}}=N_{C L_{\max }}-\frac{\left(A F F_{\max }-A F F_{i}\right) \cdot\left(N_{C L_{\max }}-N_{C L_{\min }}\right)}{A F F_{\max }-A F F_{\min }+\varepsilon} ; \quad N_{C L_{i}} \in \mathbb{N}
$$


Created clones are then subjected to a hypermutation process, inversely proportional to the affinity of the antibody. The probability of mutation of an antibody is determined as follows:

$$
P_{M U T_{i}}=P_{M U T_{\text {min }}}+\frac{\left(A F F_{\text {max }}-A F F_{i}\right) \cdot\left(P_{M U T_{\text {max }}}-P_{M U T_{\text {min }}}\right)}{A F F_{\text {max }}-A F F_{\text {min }}+\varepsilon}
$$

In the classical variant of the CLONALG, the mutation operator generates $r=N \cdot l$ pseudo-random numbers between 0 and 1 . For binary problem representation, mutation of a single bit in an antibody occurs when the generated pseudo-random number is less or equal to the probability of mutation. The presented scheme of the hypermutation operator operation shows that with a sufficiently high probability value, all bits in the analyzed antibody can undergo mutation. This article presents a modification of the hypermutation operator to enable changing the value of only a single bit in a given antibody. The modification consists of the fact that the number of generated pseudo-random numbers on the basis of which the algorithm decides whether to make a mutation has been limited to $r=N$. In case the generated pseudo-random number is less than the probability of mutation, a second pseudo-random generator is launched, which randomizes an integer ranging from 1 to 1 . The generated second pseudo-random number is the position of the bit being mutated. The operation diagram of the modified hypermutation operator is shown in Figure 2.

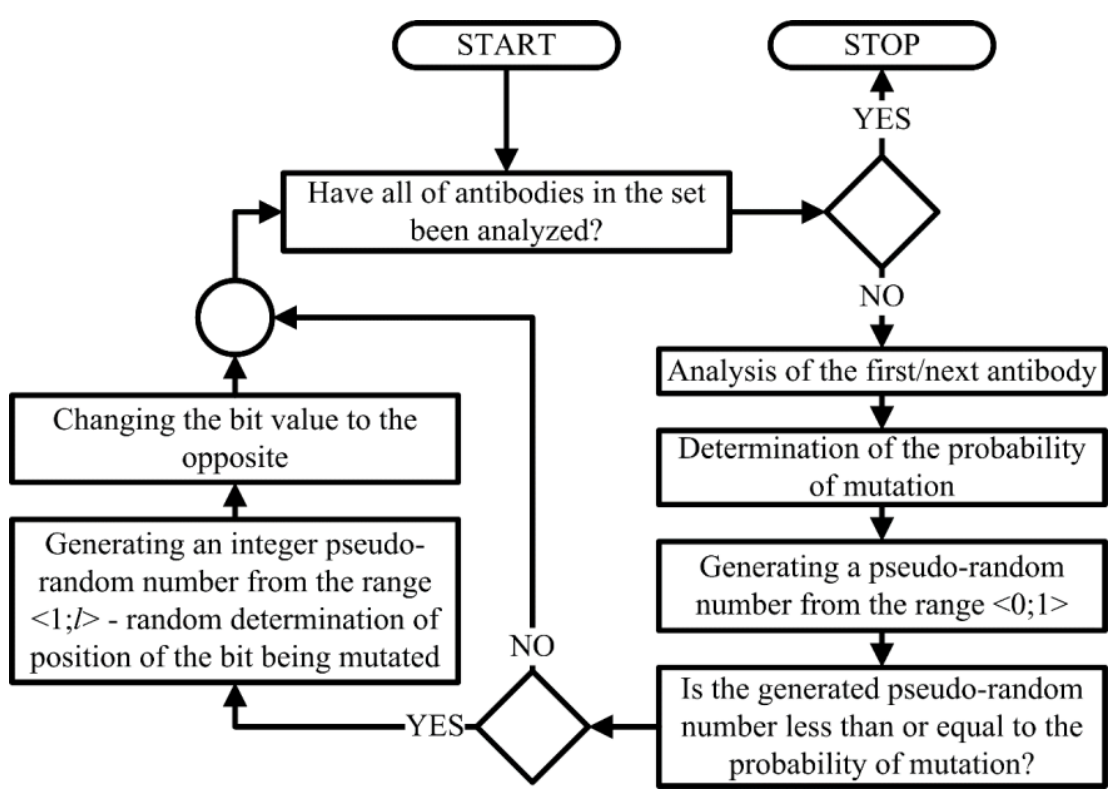

Figure 2. Operation diagram of the modified hypermutation operator.

After the hypermutation operation, the modified clones are added to the antibody set. To prevent excessive growth of the set of antibodies, the algorithm removes N2 antibodies with the lowest affinity, and then complements the free spots in the set with new, randomly generated antibodies. Then the algorithm goes to the next iteration by re-determining the operating states of individual devices installed in the microgrid. The algorithm's operation cycle is repeated until the stop condition is reached. The last step performed by the algorithm is to save the results of the optimization calculations.

The optimization algorithm was implemented using the DPL script language included in the PowerFactory v.15.2 software [31]. Ranges of settings of individual devices in the microgrid and ESDs SOC are loaded once after the script has been started. Generation profiles of RES and power demand profiles of consumers are cyclically loaded for each of the optimization periods considered. All mentioned input data are saved in appropriate text files. Changing the settings of parameters controlling the operation of the algorithm 
and economic quantities, such as electricity purchase prices or per unit fixed costs, is made directly in the source code of the script implementing the optimization algorithm. The general block diagram of the script implementing the optimization algorithm, taking into account the above description, is presented in Figure 3.

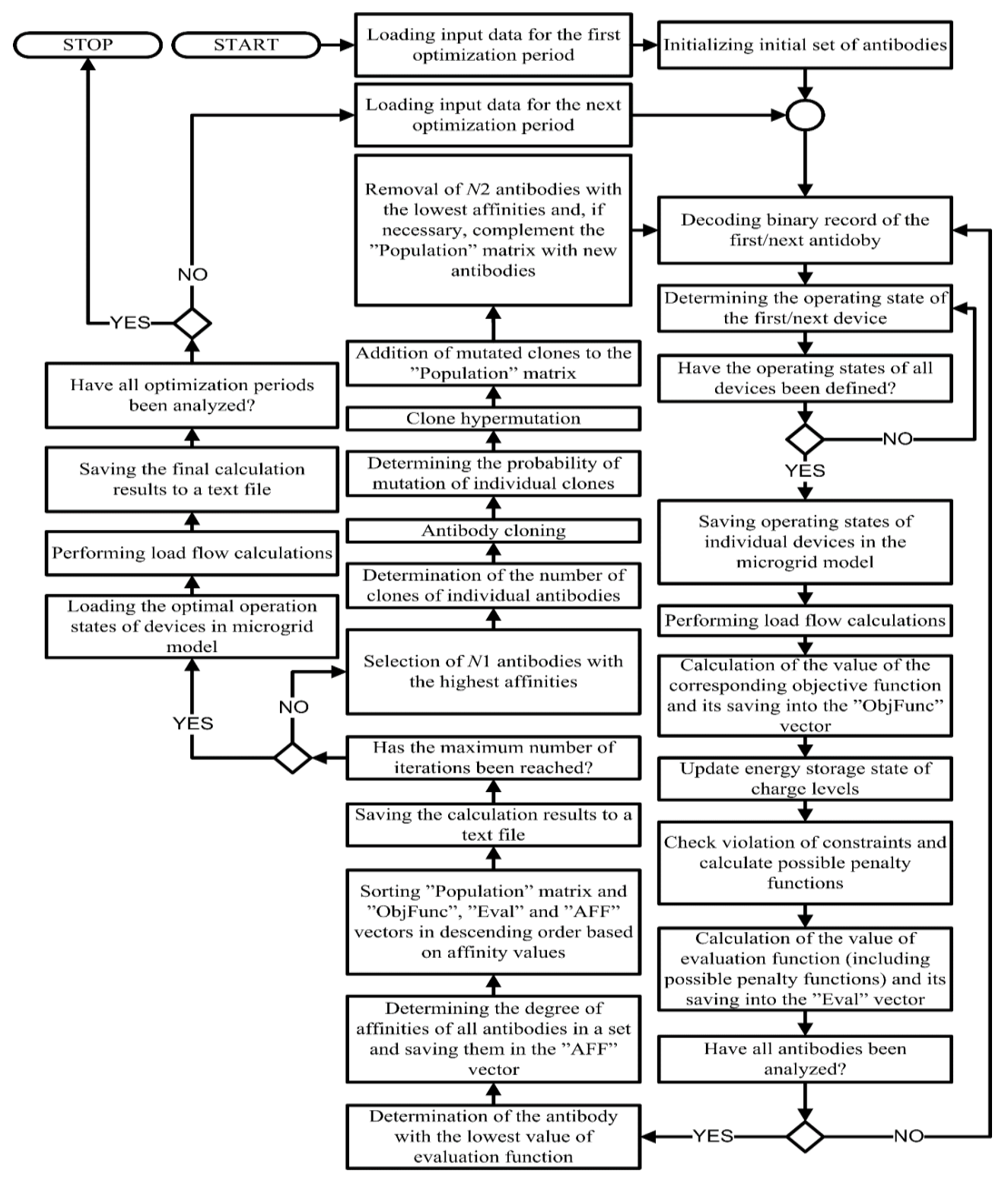

Figure 3. General block diagram of the script implementing the optimization algorithm.

\section{Case Study}

In order to evaluate the possibility of using the CLONALG with a modified hypermutation operator in the process of optimizing the configuration and operating states of the hybrid microgrid, exemplary calculations were carried out in the test microgrid working synchronously with the distribution power grid and in island mode. The optimization calculations were repeated using the CLONALG with the classic variation of the hypermutation operator and the evolutionary algorithm to compare the obtained results and verify the correct operation of modified CLONALG algorithm. Sample results of the calculations carried out are presented later in this paper. 


\subsection{Description of Test Hybrid Microgrid}

Optimization calculations were carried out for a hybrid test microgrid supplying a single-family house estate. It is a microgrid consisting of AC and DC networks connected to each other with an EPC. Individual nodes of both types of network were connected by overhead lines. DC power lines were built as double-track AsXS $2 \times 70$ type lines and AC power lines were built as single AsXS $4 \times 70$ type lines. The AC network is connected to the external distribution grid via MV/LV transformer and AFL6 35 type medium voltage line. The technical data of individual elements of the hybrid test microgrid are given in Table 1. The schematic diagram of the test microgrid is presented in Figure 4.

Table 1. Technical data of individual elements of the hybrid test microgrid.

\begin{tabular}{|c|c|c|c|c|c|c|}
\hline \multirow{2}{*}{ EPC } & $\mathrm{S}_{\mathrm{n}}[\mathrm{kVA}]$ & $\mathrm{U}_{\mathrm{AC}}[\mathrm{kV}]$ & $\mathrm{U}_{\mathrm{DC}}[\mathrm{kV}]$ & $\cos \varphi_{\mathrm{n}}[-]$ & $\Delta \mathrm{P}_{\text {Load }}[\mathrm{kW}]$ & $\Delta \mathrm{P}_{\text {Idle }}[\mathrm{kW}]$ \\
\hline & 125 & 0.4 & 0.4 & 0.8 & 5 & 0.5 \\
\hline \multirow{2}{*}{ MV/LV Transformer } & $\mathrm{S}_{\mathrm{n}}[\mathrm{kVA}]$ & $\mathrm{U}_{\mathrm{MV}}[\mathrm{kV}]$ & $\mathrm{U}_{\mathrm{LV}}[\mathrm{kV}]$ & $\Delta \mathrm{U}_{\mathrm{k}}[\%]$ & $\Delta \mathrm{P}_{\mathrm{Cu}}[\mathrm{kW}]$ & $\Delta \mathrm{P}_{\mathrm{Fe}}[\mathrm{kW}]$ \\
\hline & 63 & 15.75 & 0.4 & 4.5 & 1.2 & 0.18 \\
\hline \multirow{2}{*}{ AC line AsXS $4 \times 70$} & $\mathrm{R}^{\prime}\left[\frac{\Omega}{\mathrm{km}}\right]$ & $X^{\prime}\left[\frac{\Omega}{\mathrm{km}}\right]$ & $\mathrm{I}_{\mathrm{dd}}[\mathrm{A}]$ & & & \\
\hline & 0.443 & 0.083 & 213 & & & \\
\hline \multirow{2}{*}{ MV line AFL6 35} & $\mathrm{R}^{\prime}\left[\frac{\Omega}{\mathrm{km}}\right]$ & $X^{\prime}\left[\frac{\Omega}{\mathrm{km}}\right]$ & $\mathrm{I}_{\mathrm{dd}}[\mathrm{A}]$ & & & \\
\hline & 0.852 & 0.4 & 145 & & & \\
\hline \multirow{2}{*}{ DC line AsXS $2 \times 70$} & $\mathrm{R}^{\prime}\left[\frac{\Omega}{\mathrm{km}}\right]$ & $\mathrm{I}_{\mathrm{dd}}[\mathrm{A}]$ & & & & \\
\hline & 0.443 & 213 & & & & \\
\hline
\end{tabular}

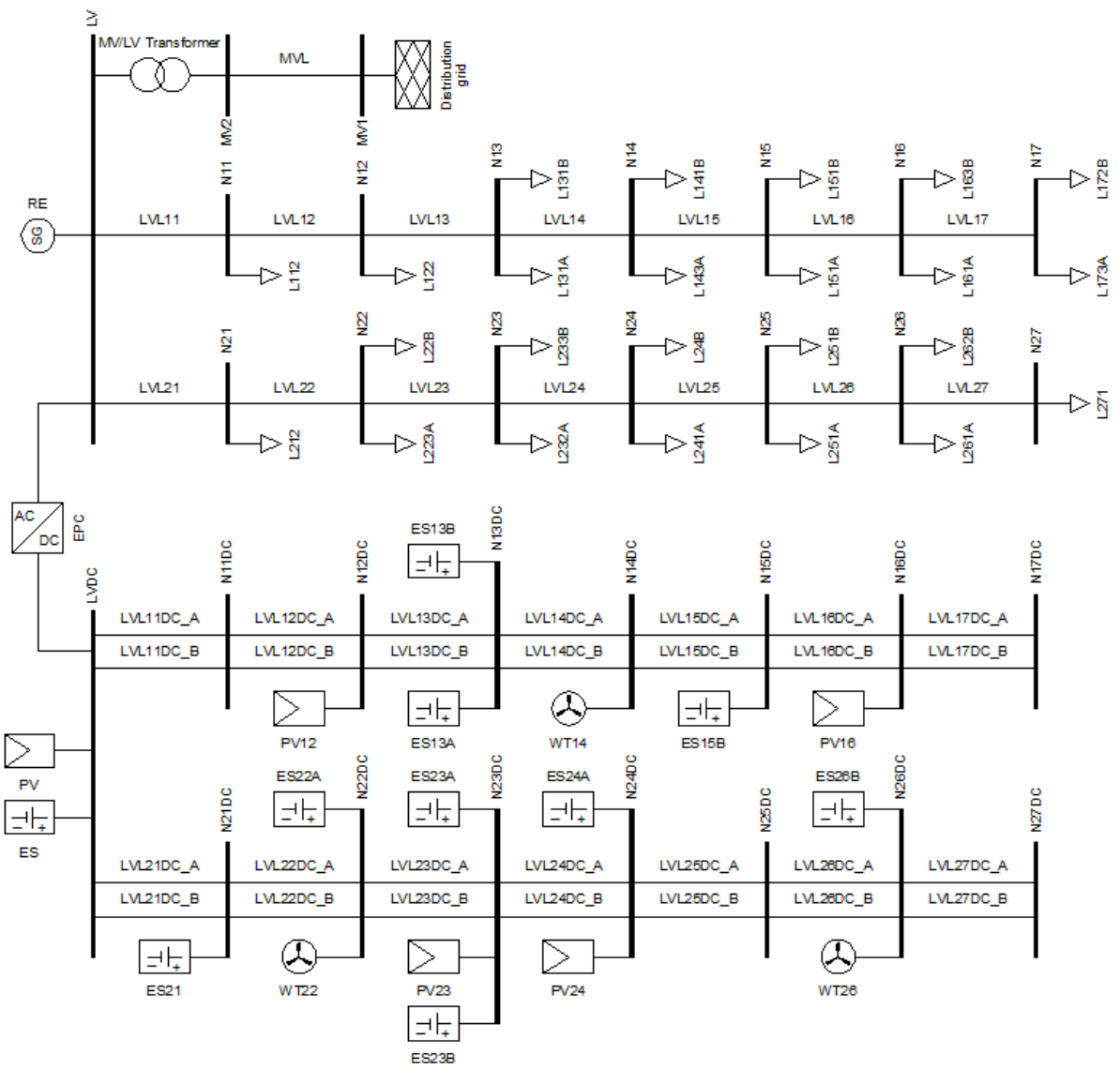

Figure 4. Schematic diagram of the test microgrid. 
In a hybrid test microgrid, 24 non-controlled loads connected only to the AC network were modeled. Each of the load was characterized by assigning to it one of three different daily active and reactive power demand characteristics. The total daily power demand characteristics of the test microgrid are presented in Figure 5.

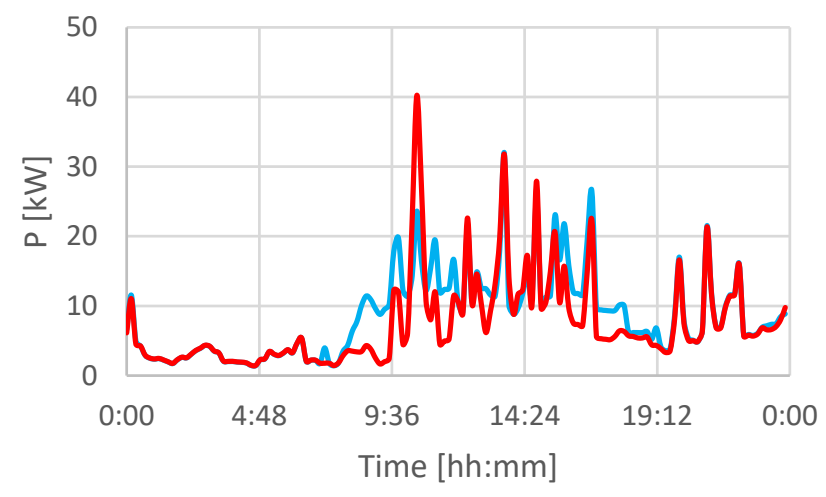

— working day holiday

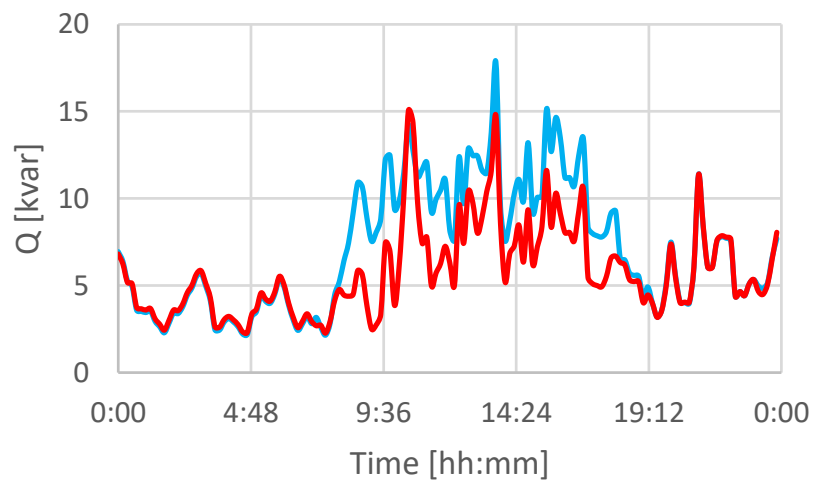

— working day holiday

(a)

(b)

Figure 5. (a) Total daily active power demand characteristics of the test microgrid; (b) Total daily reactive power demand characteristics of the test microgrid.

The hybrid test microgrid was equipped with 9 microsources, divided into three categories (1 reciprocating engine (RE) with synchronous generator connected directly to the AC network, 3 wind microturbine generation sets, and 5 photovoltaic sources connected to the DC network via power inverters). Technical data of installed microsources are presented in Table 2. Daily characteristics of photovoltaic sources and wind microturbine generation sets' generation capacity for two selected days of the year are presented in Figure 6.

Table 2. Technical data of the microsources installed in the hybrid test microgrid.

\begin{tabular}{ccccccc}
\hline Microsource & Owner & $\begin{array}{c}\text { Nominal Power } \\
{\left[\mathbf{k W ]} /[\mathbf{k V A}]^{*}\right.}\end{array}$ & $\begin{array}{c}\mathbf{P}_{\min } \\
{[\mathbf{k W}]}\end{array}$ & $\begin{array}{c}\mathbf{P}_{\max } \\
{[\mathbf{k W}]}\end{array}$ & $\begin{array}{c}\mathbf{Q}_{\min } \\
{[\mathbf{k v a r}]}\end{array}$ & $\begin{array}{c}\mathbf{Q}_{\max } \\
{[\mathbf{k v a r}]}\end{array}$ \\
\hline AP & HMO & 61 & 0 & 49 & -36.7 & 36.7 \\
PV & HMO & 40 & 0 & It depends & 0 & 0 \\
PV12 & Consumer & 4 & 0 & on the & 0 & 0 \\
PV16 & Consumer & 25 & 0 & atmospheric & 0 & 0 \\
PV23 & Consumer & 6 & 0 & conditions & 0 & 0 \\
PV24 & Consumer & 10 & 0 & prevailing in & 0 & 0 \\
TW14 & Consumer & 2 & 0 & a given & 0 & 0 \\
TW22 & Consumer & 5 & 0 & optimization & 0 & 0 \\
TW26 & Consumer & 3 & 0 & period & 0 & 0 \\
\hline
\end{tabular}

* apparent power for the microsource connected to the AC network, active power for the microsource connected to the DC network.

For microsources owned by the HMO, fixed costs per unit of $0.0014 \mathrm{USD} / \mathrm{kW} / \mathrm{T}$ were adopted, where $T$ is an optimization period of $10 \mathrm{~min}$. HMO is not charged with fixed costs resulting from the maintenance of microsources owned by individual consumers. Variable costs per unit of the reciprocating engine were adopted at the level of $0.0279 \mathrm{USD} / \mathrm{kW} / \mathrm{T}$; it was also assumed that this value constitutes the purchase price of energy generated in microsources owned by individual consumers. Variable costs of the HMOs photovoltaic source are zero. The regulation of the generated power level of photovoltaic sources and wind microturbine generation sets is carried out by detuning the converter connecting the 
source with the hybrid microgrid from the maximum power operation point (MPP) on the production characteristics of the given source [32].

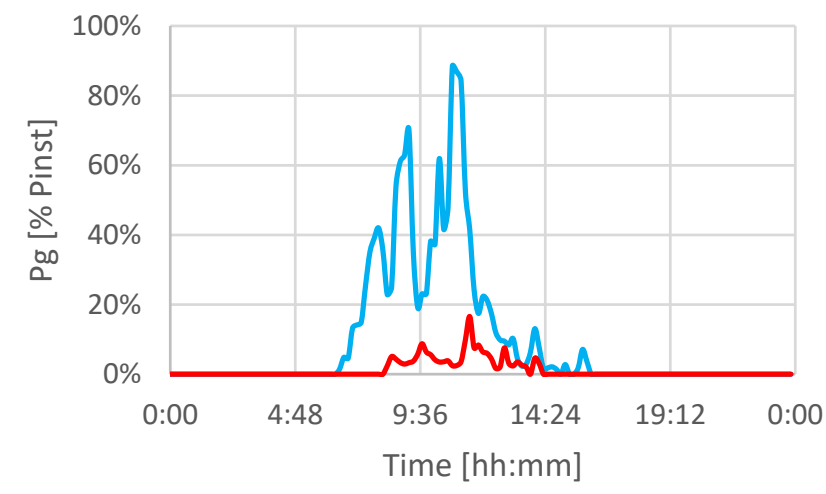

- 02.03.2017 -

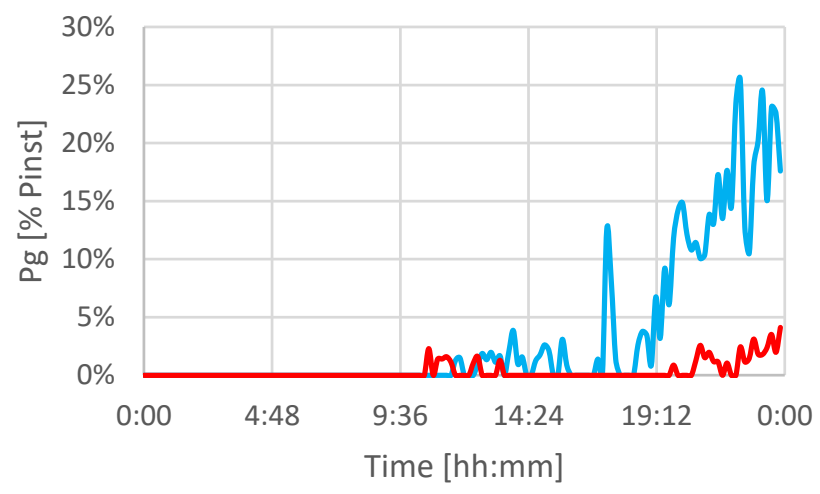

- 02.03.2017 -10.12.2017

(a)

(b)

Figure 6. (a) Daily generation capacity charecteristics of photovoltaic sources; (b) Daily generation capacity characteristics of wind microturbine generation sets.

The test microgrid was equipped with 9 ESDs with a rated power of $50 \mathrm{~kW}$ and a capacity of $37 \mathrm{kWh}$, owned by individual consumers. The HMO also has one energy storage device with a rated power of $40 \mathrm{~kW}$ and a capacity of $160 \mathrm{kWh}$. All ESDs have been connected only to the DC network. In the process of controlling ESDs, it was assumed that they could operate in the full range of power regulation. However, the charge or discharge power may be reduced if the energy level in the storage device is not within acceptable limits. These limits are:

- from 5\% to $95 \%$ of the storage capacity between $12: 00$ am to $6: 50 \mathrm{pm}$,

- from $40 \%$ to $60 \%$ of the storage capacity between 7:00 pm to 11:50 pm.

The greater reduction on the SOC of ESDs in the evening is designed to prepare them for operation during the next day, so that they are able to balance the shortage or surplus of generated power in microsources in relation to the power demand of customers. As in the case of microsources, the $\mathrm{HMO}$ is not charged with fixed costs resulting from the maintenance of consumers ESDs. Consumers have full freedom in the choice of energy storage technology and capacity, which forces HMO to maintain the appropriate infrastructure enabling the connection of the storage device to the network. It has been assumed that the costs per unit of maintaining a single connection is $0.004 \mathrm{USD} / \mathrm{kW} / \mathrm{T}$. The same numerical value is a fixed costs per unit for the energy storage device owned by HMO. HMOs variable costs include per unit costs of discharging energy storage device, amounting to $0.0095 \mathrm{USD} / \mathrm{kW} / \mathrm{T}$. The price from the sale of energy taken to charge storage devices belonging to the consumers amounts to $0.0322 \mathrm{USD} / \mathrm{kW} / \mathrm{T}$ and it is HMO revenue.

It should also be noted that the energy storage device owned by $\mathrm{HMO}$ is not subject to optimization. The device works as a source balancing the DC network. The use of energy storage as a balancing element of the DC network allows optimization of the operating states of the EPC connecting both DC and AC networks, which translates into control of power flow between both networks. In the case of island operation of the hybrid microgrid, the reciprocating engine was excluded from the optimization process, also to assign the role of balancing source to this device.

\subsection{Results of Optimization Calculations Carried out Using the Modified CLONALG Algorithm}

In order to obtain the results of optimization calculations, a $24 \mathrm{~h}$ microgrid operation simulations were performed for a test microgrid. Simulations were made for both 
synchronous and island operation. Two different load demand profiles for working day and for holiday were taken into account, as well as two generation profiles for RES for 2 March 2017 and 10 December 2017. In total, eight simulations were carried out for a single optimization task. Each of the simulations was started for the same initial ESDs SOC levels and the following settings of the algorithm control parameters:

- number of antibodies: $N=400$,

- number of antibodies selected for cloning: $N_{1}=40$,

- number of antibodies replaced by randomly generated new antibodies: $N_{2}=16$,

- maximum probability of mutation: $P_{m u t \_m a x}=0.53$,

- minimum probability of mutation: $P_{\text {mut_min }}=0.19$,

- maximum number of clones created for single antibody: $N_{C L_{\max }}=4$,

- minimum number of clones created for single antibody: $N_{C L_{\min }}=2$.

The number of iterations of the optimization algorithm depended on the chosen optimization tasks and microgrid operation mode; detailed values are given in Table 3.

Table 3. Number of iterations of the optimization algorithm.

\begin{tabular}{ccc}
\hline Optimization Task & Synchronous Operation & Island Operation \\
\hline Task 1 & 200 & 200 \\
Task 2 & 200 & 450 \\
Task 3 & 150 & 250 \\
\hline
\end{tabular}

Selected results of optimization calculations (for a single optimization period) are presented in Tables 4-6. Exemplary daily changes of optimized values for the adopted generation profile of 2 March 2017 and power demand profile for the working day are presented in Figures 7-9.

Table 4. Selected results of optimization calculations in task 1 .

\begin{tabular}{|c|c|c|c|c|c|c|}
\hline \multirow{2}{*}{$\begin{array}{l}\text { Test Microgrid } \\
\text { Operation } \\
\text { Mode }\end{array}$} & \multirow[b]{2}{*}{ Time } & \multirow{2}{*}{$\begin{array}{l}\text { RES Generation } \\
\text { Profiles Date }\end{array}$} & \multirow[b]{2}{*}{ Day Type } & \multirow{2}{*}{$\begin{array}{c}\text { Optimized Quality } \\
\text { Indicator } \\
\begin{array}{c}\text { Active Power Losses } \\
{[\mathrm{kW}]}\end{array}\end{array}$} & \multicolumn{2}{|c|}{ Other Quality Indicators } \\
\hline & & & & & Costs [USD] & $\begin{array}{l}\text { Level of Power } \\
\text { Generated in } \\
\text { RES }[\mathrm{kW}]\end{array}$ \\
\hline \multirow{4}{*}{ Synchronous } & \multirow{4}{*}{$10: 50 \mathrm{am}$} & \multirow{2}{*}{2 March 2017} & working day & 1.086 & 3.565 & 35.550 \\
\hline & & & Holiday & 0.839 & 3.766 & 15.468 \\
\hline & & \multirow{2}{*}{10 December 2017} & working day & 1.081 & 2.977 & 0.754 \\
\hline & & & holiday & 1.421 & 2.958 & 1.147 \\
\hline \multirow{4}{*}{ Island } & \multirow{4}{*}{$5: 30 \mathrm{am}$} & \multirow{2}{*}{2 March 2017} & working day & 1.346 & 3.338 & 0.000 \\
\hline & & & holiday & 1.161 & 3.578 & 0.000 \\
\hline & & \multirow{2}{*}{10 December 2017} & working day & 1.293 & 3.204 & 0.000 \\
\hline & & & holiday & 1.670 & 3.454 & 0.000 \\
\hline
\end{tabular}


Table 5. Selected results of optimization calculations in task 2 .

\begin{tabular}{|c|c|c|c|c|c|c|}
\hline \multirow{2}{*}{$\begin{array}{l}\text { Test Microgrid } \\
\text { Operation } \\
\text { Mode }\end{array}$} & \multirow[b]{2}{*}{ Time } & \multirow{2}{*}{$\begin{array}{l}\text { RES Generation } \\
\text { Profiles Date }\end{array}$} & \multirow[b]{2}{*}{ Day Type } & \multirow{2}{*}{$\begin{array}{c}\begin{array}{c}\text { Optimized Quality } \\
\text { Indicator }\end{array} \\
\text { Costs [USD] }\end{array}$} & \multicolumn{2}{|c|}{ Other Quality Indicators } \\
\hline & & & & & $\begin{array}{l}\text { Active Power } \\
\text { Losses }[k W]\end{array}$ & $\begin{array}{l}\text { Level of Power } \\
\text { Generated in } \\
\text { RES [kW] }\end{array}$ \\
\hline \multirow{4}{*}{ Synchronous } & \multirow{4}{*}{$10: 50 \mathrm{am}$} & \multirow{2}{*}{2 March 2017} & working day & 3.304 & 1.231 & 0.000 \\
\hline & & & holiday & 2.707 & 0.927 & 4.678 \\
\hline & & \multirow{2}{*}{10 December 2017} & working day & 3.053 & 2.515 & 0.000 \\
\hline & & & holiday & 3.267 & 2.130 & 0.000 \\
\hline \multirow{4}{*}{ Island } & \multirow{4}{*}{$5: 30 \mathrm{am}$} & \multirow{2}{*}{2 March 2017} & working day & 2.601 & 0.886 & 0.000 \\
\hline & & & holiday & 2.657 & 0.956 & 0.000 \\
\hline & & \multirow{2}{*}{10 December 2017} & working day & 3.094 & 1.235 & 0.000 \\
\hline & & & holiday & 2.657 & 0.956 & 0.000 \\
\hline
\end{tabular}

Table 6. Selected results of optimization calculations in task 3.

\begin{tabular}{|c|c|c|c|c|c|c|}
\hline \multirow{2}{*}{$\begin{array}{l}\text { Test Microgrid } \\
\text { Operation } \\
\text { Mode }\end{array}$} & \multirow{2}{*}{ Time } & \multirow{2}{*}{$\begin{array}{l}\text { RES Generation } \\
\text { Profiles Date }\end{array}$} & \multirow{2}{*}{ Day Type } & \multirow{2}{*}{$\begin{array}{c}\text { Optimized Quality } \\
\text { Indicator }\end{array}$} & \multicolumn{2}{|c|}{ Other Quality Indicators } \\
\hline & & & & & $\begin{array}{l}\text { Costs } \\
\text { [USD] }\end{array}$ & $\begin{array}{c}\text { Active Power } \\
\text { Losses }[\mathrm{kW}]\end{array}$ \\
\hline \multirow{4}{*}{ Synchronous } & \multirow{4}{*}{$10: 50 \mathrm{am}$} & \multirow{2}{*}{2 March 2017} & working day & 29.576 & 4.681 & 3.774 \\
\hline & & & holiday & 62.094 & 5.230 & 3.148 \\
\hline & & \multirow{2}{*}{10 December 2017} & working day & 1.702 & 3.586 & 1.495 \\
\hline & & & holiday & 1.696 & 4.525 & 3.039 \\
\hline \multirow{4}{*}{ Island } & \multirow{4}{*}{$5: 30 \mathrm{am}$} & \multirow{2}{*}{2 March 2017} & working day & 0.000 & 3.602 & 1.499 \\
\hline & & & holiday & 0.000 & 3.602 & 1.499 \\
\hline & & \multirow{2}{*}{10 December 2017} & working day & 0.000 & 3.602 & 1.499 \\
\hline & & & holiday & 0.000 & 3.602 & 1.499 \\
\hline
\end{tabular}

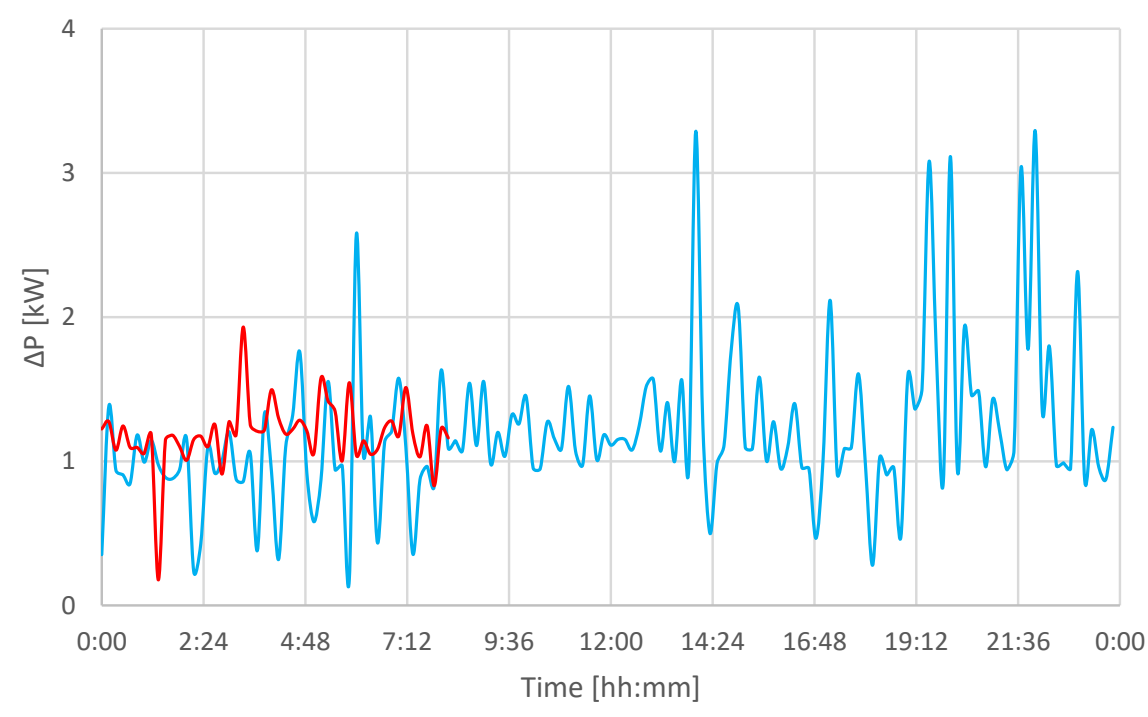

_Synchronous operation _ Island Operation

Figure 7. Daily changes of active power losses. 


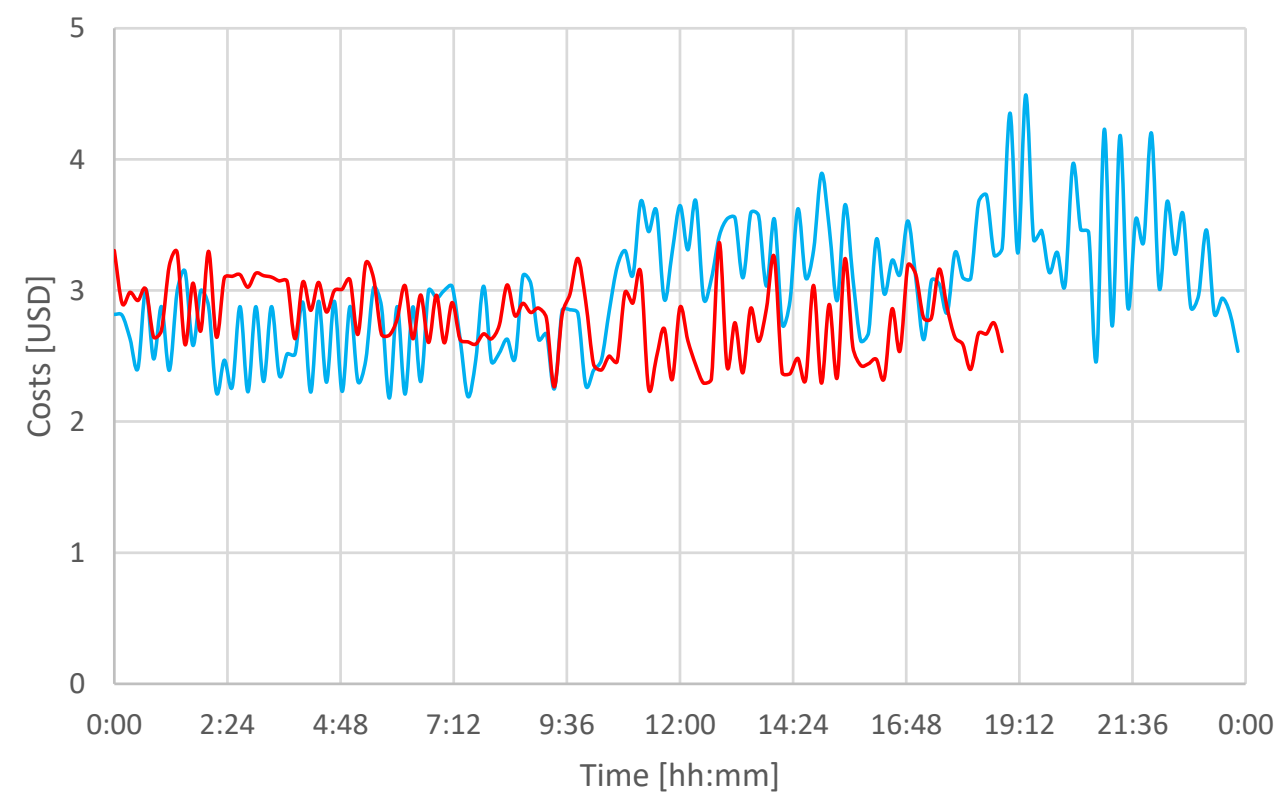

_Synchronous operation __land operation

Figure 8. Daily changes of costs of operation of the hybrid test microgrid.

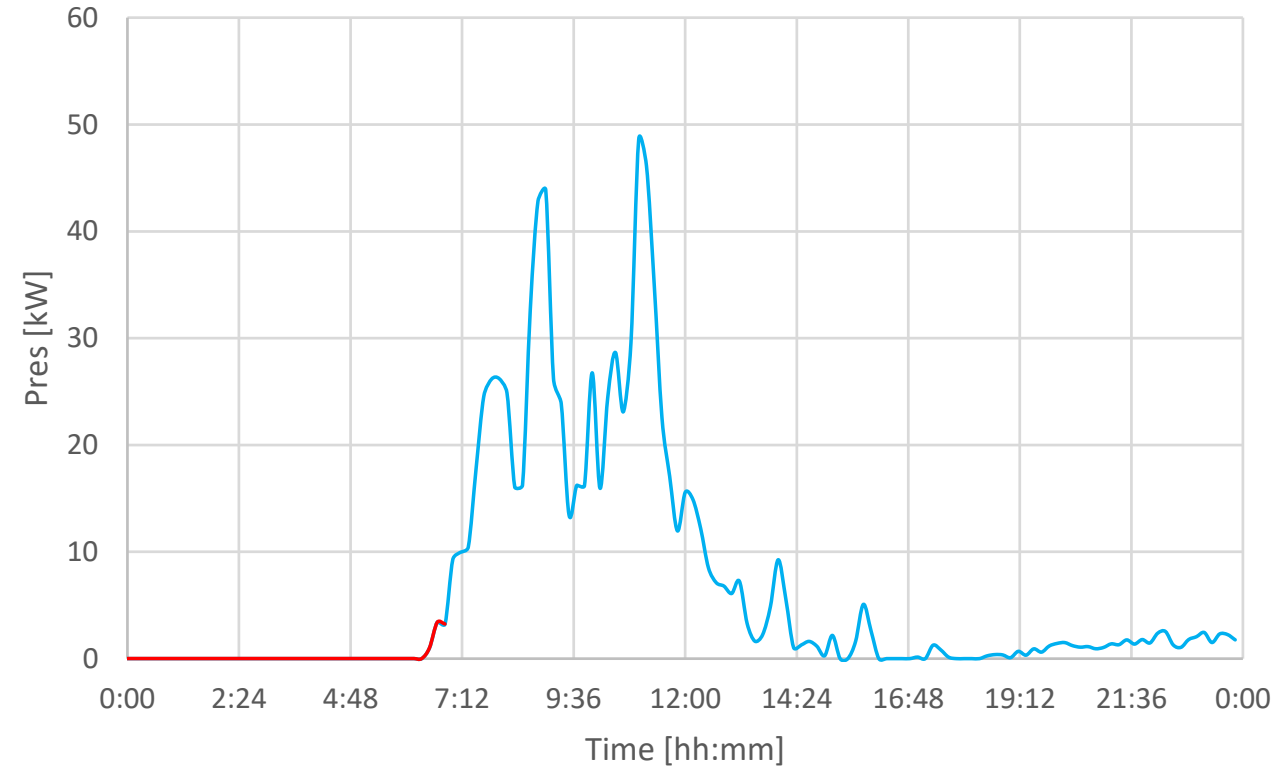

Figure 9. Daily changes of active power generated in RES.

Figure 10 presents the changes in the value of the evaluation function in task 1 for a microgrid operating synchronously with the distribution network depending on the selected RES generation capacity profile, and the power demand profile (the figure shows calculation made at 10:50 am). 

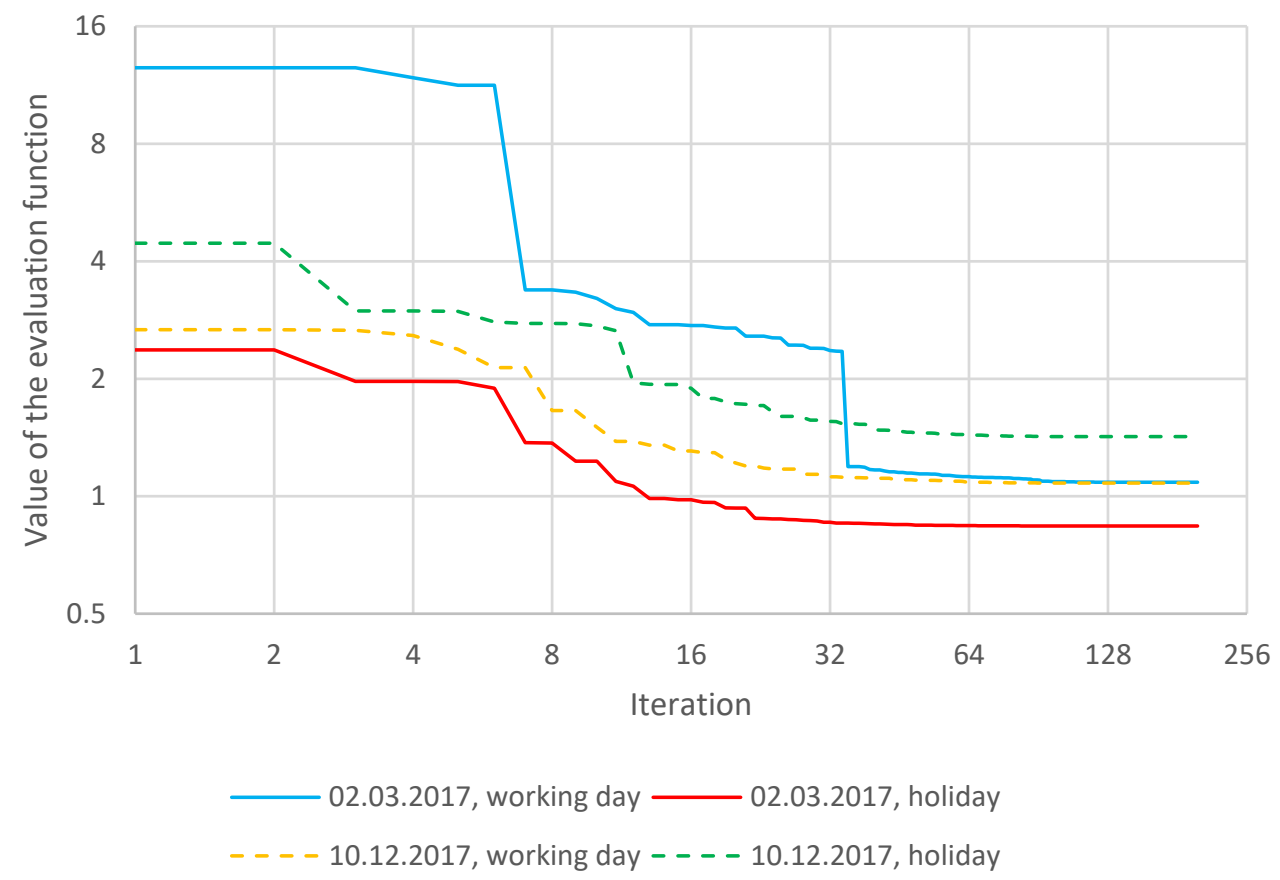

Figure 10. Progress of the optimization process.

Exemplary daily changes of the operating states of a selected microsource for a microgrid operating synchronously with the distribution network depending on the RES generation capacity profile of 2 March 2017 and the power demand profile for a working day are shown in Figure 11.

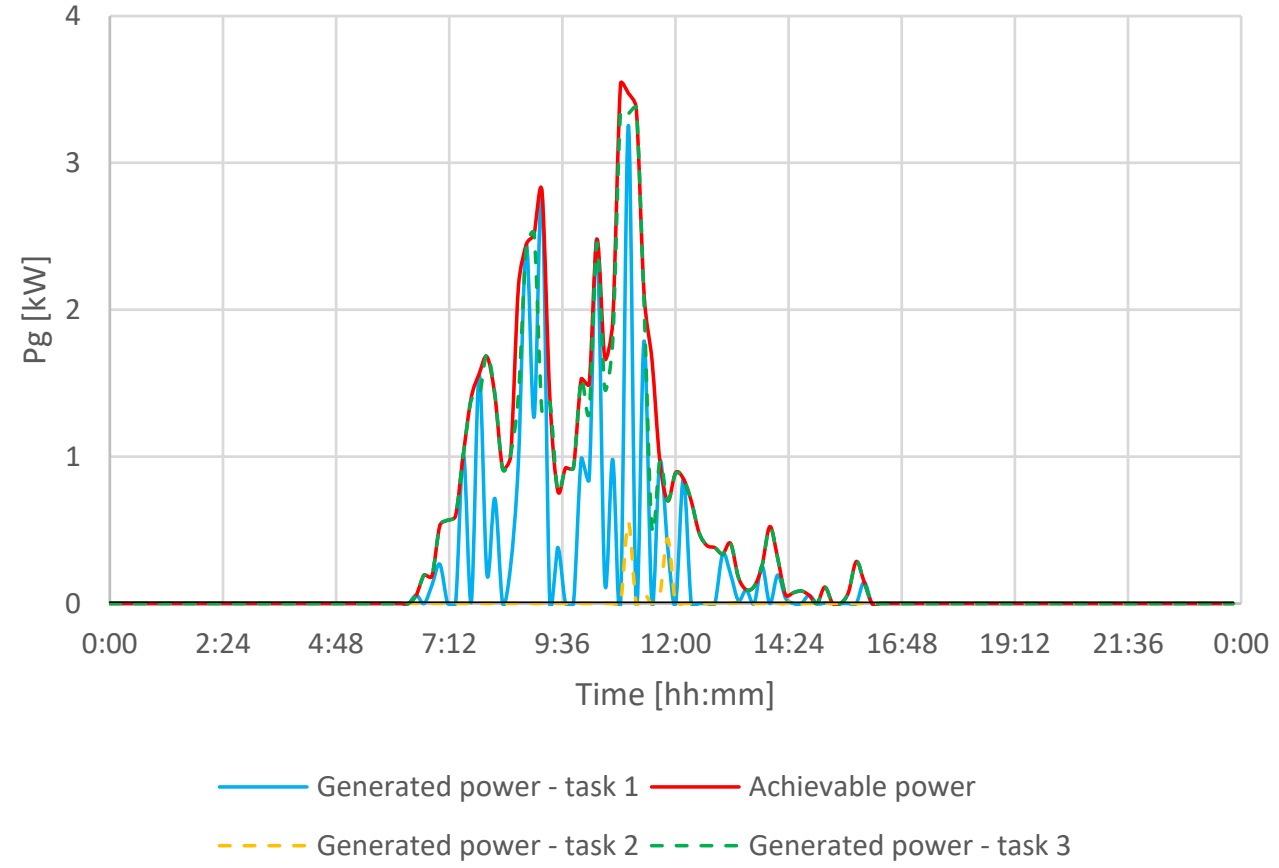

Figure 11. Daily changes of the operating states of the selected microsource (PV12).

4.3. Comparison of Calculation Results Obtained Using the CLONALG Algorithm and the Evolutionary Algorithm

Due to the modification of the hypermutation operator used in the CLONALG and the wish to verify the obtained optimization results, a comparative analysis of these results was carried out with the results obtained using the evolutionary algorithm, which is com- 
monly used to solve optimization tasks in the field of power engineering [33-37]. In the evolutionary algorithm used for comparison, a stochastic sampling with replacement was used as a selection method. A binary representation of the problem, identical to the CLONALG, was also assumed. Within the control parameters of the evolutionary algorithm, a crossover probability of 0.22 and a mutation probability of 0.07 were assumed. The number of chromosomes was equal to the number of antibodies defined in the CLONALG and both algorithms performed the same number of iterations within the considered optimization period. The results of the comparison are shown in Tables 7 and 8.

Table 7. Comparison of results of optimization calculations for the microgrid synchronous operation.

\begin{tabular}{|c|c|c|c|c|c|c|}
\hline \multirow[b]{2}{*}{$\begin{array}{l}\text { Optimization } \\
\text { Task }\end{array}$} & \multirow[b]{2}{*}{$\begin{array}{l}\text { RES Generation } \\
\text { Capacity Profile }\end{array}$} & \multirow[b]{2}{*}{$\begin{array}{l}\text { Power } \\
\text { Demand } \\
\text { Profile }\end{array}$} & \multicolumn{3}{|c|}{ Percentage of Optimization Periods at Which: } & \multirow[b]{2}{*}{$\begin{array}{c}\text { Number of } \\
\text { Analyzed } \\
\text { Optimization } \\
\text { Periods }\end{array}$} \\
\hline & & & $\begin{array}{c}\text { CLONALG } \\
\text { Algorithm } \\
\text { Achieved a } \\
\text { Better Solution }\end{array}$ & $\begin{array}{l}\text { Evolutionary } \\
\text { Algorithm } \\
\text { Achieved a } \\
\text { Better Solution }\end{array}$ & $\begin{array}{l}\text { Both Algorithms } \\
\text { Reached an } \\
\text { Identical } \\
\text { Solution }\end{array}$ & \\
\hline \multirow{4}{*}{ Task 1} & \multirow{2}{*}{2 March 2017} & working day & $83.33 \%$ & $16.67 \%$ & $0.00 \%$ & 144 \\
\hline & & holiday & $79.86 \%$ & $20.14 \%$ & $0.00 \%$ & 144 \\
\hline & \multirow{2}{*}{10 December 2017} & working day & $86.81 \%$ & $13.19 \%$ & $0.00 \%$ & 144 \\
\hline & & holiday & $79.86 \%$ & $20.14 \%$ & $0.00 \%$ & 144 \\
\hline \multirow{4}{*}{ Task 2} & \multirow{2}{*}{2 March 2017} & working day & $91.67 \%$ & $8.33 \%$ & $0.00 \%$ & 144 \\
\hline & & holiday & $91.67 \%$ & $8.33 \%$ & $0.00 \%$ & 144 \\
\hline & \multirow{2}{*}{10 December 2017} & working day & $92.36 \%$ & $7.64 \%$ & $0.00 \%$ & 144 \\
\hline & & holiday & $86.11 \%$ & $13.89 \%$ & $0.00 \%$ & 144 \\
\hline \multirow{4}{*}{ Task 3} & \multirow{2}{*}{2 March 2017} & working day & $61.81 \%$ & $2.78 \%$ & $35.42 \%$ & 144 \\
\hline & & holiday & $61.81 \%$ & $2.78 \%$ & $35.42 \%$ & 144 \\
\hline & \multirow{2}{*}{10 December 2017} & working day & $36.81 \%$ & $0.00 \%$ & $63.19 \%$ & 144 \\
\hline & & holiday & $36.81 \%$ & $0.00 \%$ & $63.19 \%$ & 144 \\
\hline
\end{tabular}

Table 8. Comparison of results of optimization calculations for the microgrid island operation.

\begin{tabular}{|c|c|c|c|c|c|c|}
\hline \multirow[b]{2}{*}{$\begin{array}{l}\text { Optimization } \\
\text { Task }\end{array}$} & \multirow[b]{2}{*}{$\begin{array}{l}\text { RES Generation } \\
\text { Capacity Profile }\end{array}$} & \multirow[b]{2}{*}{$\begin{array}{l}\text { Power } \\
\text { Demand } \\
\text { Profile }\end{array}$} & \multicolumn{3}{|c|}{ Percentage of Optimization Periods at Which: } & \multirow[b]{2}{*}{$\begin{array}{c}\text { Number of } \\
\text { Analyzed } \\
\text { Optimization } \\
\text { Periods }\end{array}$} \\
\hline & & & $\begin{array}{c}\text { CLONALG } \\
\text { Algorithm } \\
\text { Achieved a } \\
\text { Better Solution }\end{array}$ & $\begin{array}{c}\text { Evolutionary } \\
\text { Algorithm } \\
\text { Achieved a } \\
\text { Better Solution }\end{array}$ & $\begin{array}{c}\text { Both Algorithms } \\
\text { Reached an } \\
\text { Identical } \\
\text { Solution }\end{array}$ & \\
\hline \multirow{4}{*}{ Task 1} & \multirow{2}{*}{2 March 2017} & working day & $90.00 \%$ & $10.00 \%$ & $0.00 \%$ & 50 \\
\hline & & holiday & $92.16 \%$ & $7.84 \%$ & $0.00 \%$ & 51 \\
\hline & \multirow{2}{*}{10 December 2017} & working day & $93.24 \%$ & $6.76 \%$ & $0.00 \%$ & 74 \\
\hline & & holiday & $88.41 \%$ & $11.59 \%$ & $0.00 \%$ & 69 \\
\hline \multirow{4}{*}{ Task 2} & \multirow{2}{*}{2 March 2017} & working day & $100.00 \%$ & $0.00 \%$ & $0.00 \%$ & 114 \\
\hline & & holiday & $98.77 \%$ & $1.23 \%$ & $0.00 \%$ & 81 \\
\hline & \multirow{2}{*}{10 December 2017} & working day & $100.00 \%$ & $0.00 \%$ & $0.00 \%$ & 92 \\
\hline & & holiday & $98.91 \%$ & $1.09 \%$ & $0.00 \%$ & 92 \\
\hline \multirow{4}{*}{ Task 3} & \multirow{2}{*}{2 March 2017} & working day & $14.29 \%$ & $0.00 \%$ & $85.71 \%$ & 42 \\
\hline & & holiday & $11.36 \%$ & $0.00 \%$ & $88.64 \%$ & 44 \\
\hline & \multirow{2}{*}{10 December 2017} & working day & $30.77 \%$ & $0.00 \%$ & $69.23 \%$ & 52 \\
\hline & & holiday & $14.00 \%$ & $0.00 \%$ & $86.00 \%$ & 50 \\
\hline
\end{tabular}


For the selected cases, a comparison was also made with the classic version of the CLONALG algorithm. Calculations were made for:

- all defined optimization tasks,

- synchronous and island operation of the test microgrid,

- total achievable RES active power generation capacity equal to $75.225 \mathrm{~kW}$,

- total load demand for active power equal to $10.704 \mathrm{~kW}$.

The results of the comparison are shown in Table 9. Figure 12 shows the convergence of the optimization process for tasks 1 and 2.

Table 9. Comparison of results of the optimization calculations.

\begin{tabular}{|c|c|c|c|c|}
\hline \multirow[b]{2}{*}{$\begin{array}{l}\text { Test Microgrid } \\
\text { Operation Mode }\end{array}$} & \multirow[b]{2}{*}{$\begin{array}{l}\text { Optimized Quality } \\
\text { Indicator }\end{array}$} & \multirow[b]{2}{*}{$\begin{array}{l}\text { Evolutionary } \\
\text { Algorithm }\end{array}$} & \multicolumn{2}{|c|}{ CLONALG Algorithm } \\
\hline & & & $\begin{array}{l}\text { With Modified } \\
\text { Hypermutation } \\
\text { Operator }\end{array}$ & $\begin{array}{l}\text { With Classic } \\
\text { Hypermutation } \\
\text { Operator }\end{array}$ \\
\hline \multirow{3}{*}{ Synchronous } & Active power losses [kW] & 1.220 & 1.291 & 1.254 \\
\hline & Costs [USD] & 3.923 & 3.091 & 3.679 \\
\hline & Level of power generated in RES [kW] & 52.082 & 61.478 & 58.369 \\
\hline \multirow{3}{*}{ Island } & Active power losses [kW] & 1.180 & 1.031 & 1.081 \\
\hline & Costs [USD] & 3.960 & 2.871 & 3.556 \\
\hline & Level of power generated in RES [kW] & 55.774 & 61.957 & 57.875 \\
\hline
\end{tabular}

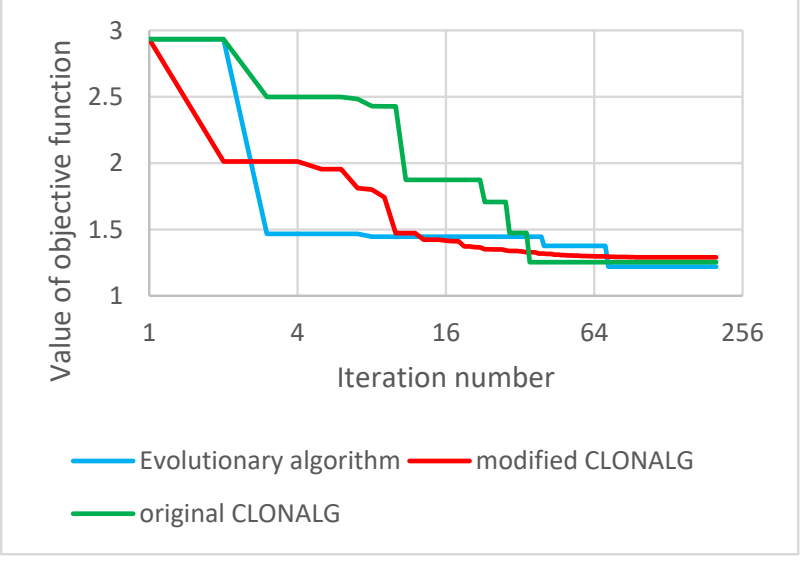

(a)

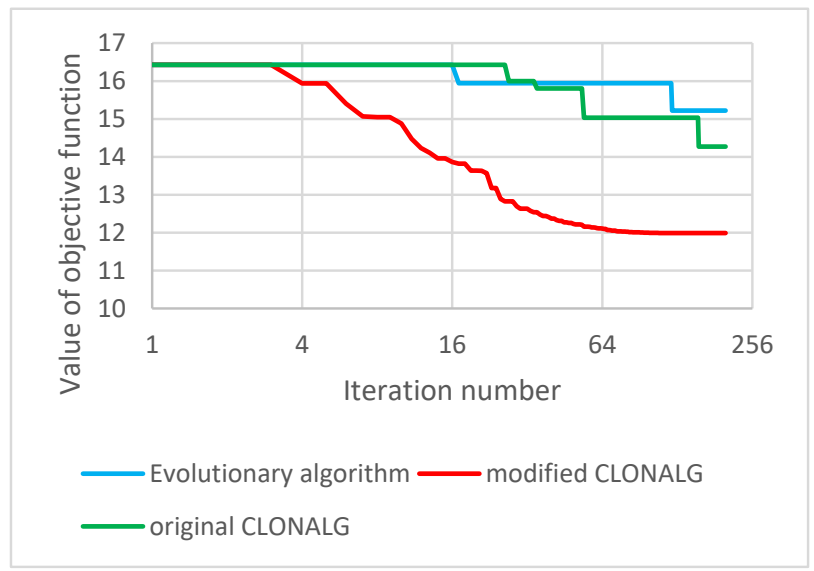

(c)
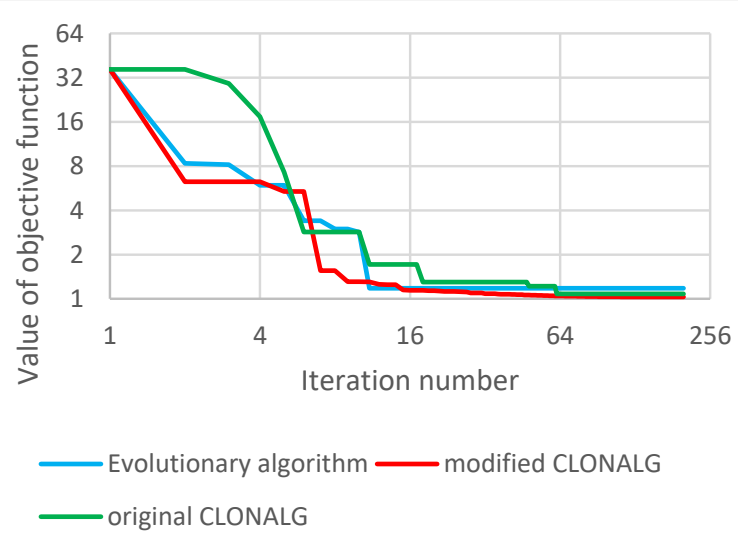

(b)
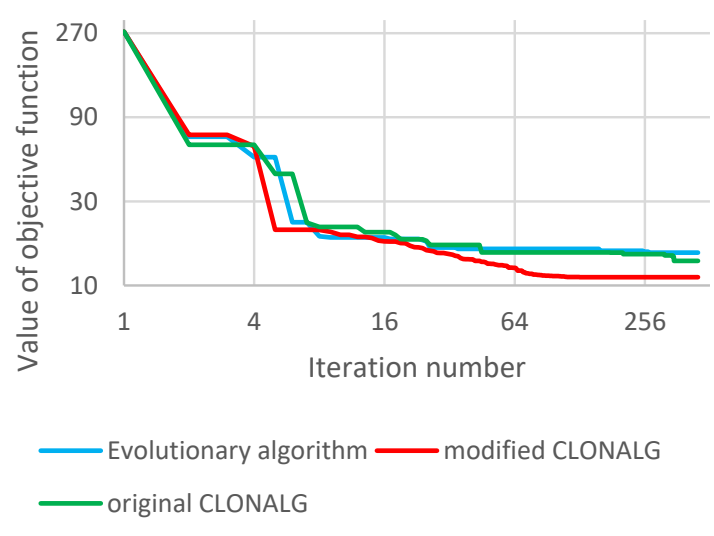

(d)

Figure 12. Convergence of optimization process for (a) task 1, synchronous operation; (b) task 1, island operation; (c) task 2 , synchronous operation; (d) task 2, island operation. 


\subsection{Discussion}

The concept of a hybrid low voltage AC/DC microgrid controlled by AIS could be an interesting way to integrate renewable energy sources, energy storage units, as well as electric vehicles into an efficient and easy to manage power microsystem.

Analyzing the results of optimization calculations constituting a $24 \mathrm{~h}$ simulation of the operation of the hybrid microgrid, it should be stated that the AIS, functioning on the basis of a CLONALG, is able to carry out the process of optimizing the configuration and operating states of the hybrid microgrid, working synchronously with the external distribution network. In case of the island operation, for all formulated optimization tasks, the algorithm was not able to ensure the correct operation of the microsystem for $24 \mathrm{~h}$. Premature termination of optimization calculations is not due to the malfunction of the AIS, but to the structures of test microgrid that were not designed for long-term island operation.

The obtained results also depend on the adopted assumptions regarding RES generation profiles and consumer power demand profiles. Analysis of the results of the optimization calculations shows that there is a relationship between the results obtained and the choice of the power demand profile. Similar conclusions can be drawn based on the analysis of various RES generation capacity profiles. In the example of the task of maximizing the level of power generated by RES, there are clear differences between generation capacities in spring and winter.

Analyzing the progress of the optimization process, it should be stated that it proceeded correctly for all considered cases. Subsequent iterations of the algorithm for solving formulated optimization tasks results in a decrease in the value of the evaluation function. The sharp decline in the value of the evaluation function in the initial iterations of the algorithm testifies to the proper functioning of the AIS and the effective elimination of suboptimal solutions. The advantage of the CLONALG over the evolutionary algorithm in the first stage of the optimization process can be due to two mechanisms:

- cloning probability directly proportional to the affinity of the antibody to antigen, combined with inverse proportional hypermutation,

- removal from the population antibodies with the lowest affinity to antigen.

The first mechanism operates by selecting a certain number of antibodies with the highest affinity (the best solution in a given iteration) and subjecting them to the cloning and hypermutation processes. The second mechanism is used to protect the algorithm against an excessive increase in population size, and thus a decrease in its efficiency, by removing the worst solutions of the optimization task and, if necessary, supplementing the population with new randomly generated antibodies. Both mechanisms mentioned above cause that in the initial phase of operation, the AIS rejects the worst solutions faster than the evolutionary algorithm.

While searching for optimal solutions for formulated tasks, the AIS changed the operating states of individual devices in the test hybrid microgrid. The way the selected microgrid element works depends to a large extent on the chosen optimization task and on the input data. For example, in task 2, the analyzed microsource (photovoltaic panel) is switched off practically throughout the simulation, while in task 3 , it works with the maximum achievable power.

A comparative analysis of optimization calculations carried out using an AIS based on a CLONALG and an evolutionary algorithm showed that for tasks 1 and 2 in most of analyzed cases more favorable results of calculations were obtained using AIS and thus the proposed optimization method is an effective optimization tool. For task number 3 , the advantage of AIS is smaller than in previous cases and for some optimization periods, both algorithms obtained identical results. This is especially visible in the case of optimization of microgrid operating in the island mode; however, it should be noted that the number of analyzed optimization periods is relatively low, compared to the optimization of the synchronously operating microgrid. 
Due to the wish to verify the modification of the hypermutation operator introduced in the CLONALG algorithm, a comparison (only for selected optimization periods) was also made with the classic version of this operator. The obtained calculation results indicate that the change in the mode of operation of the hypermutation operator resulted in an improvement of the results obtained in most of the considered cases.

When assessing the convergence of the examined optimization algorithms, it was noticed that the CLONALG algorithm with the modified hypermutation operator in most of analyzed cases gains an advantage over the other algorithms in the first few iterations of the optimization process. Further observations of the behavior of analyzed algorithms allow us to state that in the final stage of the optimization process, the differences in the obtained results are not relatively high and modified CLONALG rarely obtained worst solution. The complexity of the CLONALG algorithm, compared to the evolutionary algorithm, will require a longer computation time. This fact theoretically acts as a disadvantage of AIS as an optimization tool, but the observed tendency to remove suboptimal solution quickly in an initial stage of optimization process may be an advantage of the method proposed in this paper.

\section{Conclusions}

From the obtained results of the optimization calculations, the following conclusions can be made:

- It is possible to use an AIS based on the CLONALG algorithm as an effective optimization tool for hybrid AC/DC microgrids operating on both synchronous and island mode,

- in most of the considered cases, optimization with the use of an AIS resulted in finding a better solution compared to optimization with an evolutionary algorithm,

- the introduced modification of the hypermutation operator contributed to the improvement of the obtained results in relation to the classic version of CLONALG algorithm as well as evolutionary algorithm,

- the modified CLONALG algorithm showed a stronger tendency to reject suboptimal solutions in the early phase of the optimization process than its classic version,

- the artificial immune system, operating on the basis of the CLONALG algorithm, requires greater computational effort that the commonly used evolutionary algorithm; however, the aforementioned tendency to quickly reject suboptimal solutions at an early stage of the optimization process may be an advantage of the AIS,

- both algorithms, due to the way they work, do not guarantee that the solution they find is a global optimum. The analysis of the convergence of these algorithms suggest that the obtained solutions are a quite good approximation of the global optimum.

- the optimization tasks formulated and solved in this paper can be implemented in real installations. However, this process requires the construction of an appropriate telecommunications infrastructure that allows monitoring the state of individual microgrid elements and sending control signals to them.

The author of the article considers it advisable to conduct further research on the possibility of using AISs in solving optimization problems in the field of power engineering, especially in the field of optimization of configuration and operating states of hybrid microgrids. Another important direction of future research is also the optimization of the structure of newly design hybrid microgrids in terms of the selection of the composition of generating units, ESDs, and EPCs coupling AC and DC networks. In addition, from the IT side, research is possible to increase the efficiency of the computational algorithms used.

Funding: This research received no external funding.

Institutional Review Board Statement: Not applicable.

Informed Consent Statement: Not applicable.

Data Availability Statement: Not applicable. 
Conflicts of Interest: The authors declare no conflict of interest.

Abbreviations
$\begin{array}{ll}\text { The following } & \text { abbreviations are used in this manuscript. } \\ \text { EA } & \text { Evolutionary algorithm } \\ \text { PSO } & \text { Particle swarm optimization } \\ \text { AIS } & \text { Artificial immune systems } \\ \text { AC } & \text { Alternating current } \\ \text { DC } & \text { Direct current } \\ \text { CLONALG } & \text { Clonal selection algorithm } \\ \text { RES } & \text { Renewable energy sources } \\ \text { ESD } & \text { Energy storage device } \\ \text { EPC } & \text { Electronic power converter } \\ \text { V2G } & \text { Vehicle to grid } \\ \text { MV } & \text { Medium voltage } \\ \text { LV } & \text { Low voltage } \\ \text { SOC } & \text { State of charge } \\ \text { HMO } & \text { Hybrid microgrid operator } \\ \text { DSO } & \text { Distribution system operator } \\ \text { RE } & \text { Reciprocating engine } \\ \text { MPP } & \text { Maximum power operation point }\end{array}$

\section{Nomenclature:}

$$
\begin{aligned}
& \Delta \mathrm{P}_{\mathrm{TOT}_{\mathrm{T}}} \\
& \mathrm{N}_{\mathrm{l}} / \mathrm{N}_{\mathrm{TR}} / \mathrm{N}_{\mathrm{EPC}} \\
& \Delta \mathrm{P}_{\mathrm{l}_{\mathrm{i}}} / \Delta \mathrm{P}_{\mathrm{TR}_{\mathrm{j}}} / \Delta \mathrm{P}_{\mathrm{EPC}_{\mathrm{k}}} \\
& \mathrm{C}_{\mathrm{TOT}_{\mathrm{T}}} \\
& \mathrm{C}_{\mathrm{FIX}_{\mathrm{T}}} / \mathrm{C}_{\mathrm{VAR}_{\mathrm{T}}} \\
& \mathrm{C}_{\mathrm{FIX}_{\mathrm{DSO}}} \\
& \mathrm{C}_{\mathrm{FIX}_{\mathrm{MSHMO}}} / \mathrm{C}_{\mathrm{FIX}} \mathrm{ESHMO} \\
& \mathrm{C}_{\mathrm{FIX}_{\mathrm{MEL}}} \\
& \mathrm{C}_{\mathrm{VAR}_{\mathrm{DSO}}} \\
& \mathrm{C}_{\mathrm{VAR}_{\mathrm{MSHMO}}} / \mathrm{C}_{\mathrm{VAR}} \mathrm{CHHMO}_{\mathrm{VAR}_{\mathrm{MSL}} / \mathrm{C}_{\mathrm{VAR}}} \\
& \mathrm{P}_{\mathrm{RES}_{\mathrm{T}}} \\
& \mathrm{N}_{\mathrm{RES}_{\mathrm{i}}} \\
& \mathrm{F}_{\mathrm{O}_{\mathrm{i}}}
\end{aligned}
$$

total active power losses in the hybrid microgrid during the optimization period number of power lines/transformers/EPCs in the hybrid microgrid

active power losses in the $i$ th power line $/ j$ th transformer/ $k$ th EPC belonging to the hybrid microgrid total costs related to the operation of hybrid microgrid during the optimization period total fixed/variable costs related to the operation of hybrid microgrid during the optimization period fixed costs related to maintaining the connection of hybrid microgrid with external distribution system fixed costs related to the maintenance of microsources/ESDs owned by HMO fixed costs related to maintaining the infrastructure enabling consumers to connect microsources and ESDs to the microgrid

variable costs associated with the purchase of energy from DSO

variable costs related to the operation of microsources/ESDs owned by HMO

variable costs related to the purchase of energy generated in microsources/taken from energy storage units owned by individual customers supplied from hybrid microgrid total active power generated in RES belonging to hybrid microgrid during the optimization period number of RES installed in hybrid microgrid active power generated by $i$ th RES vector which coding a candidate solution objective function for $i$ th optimization task 


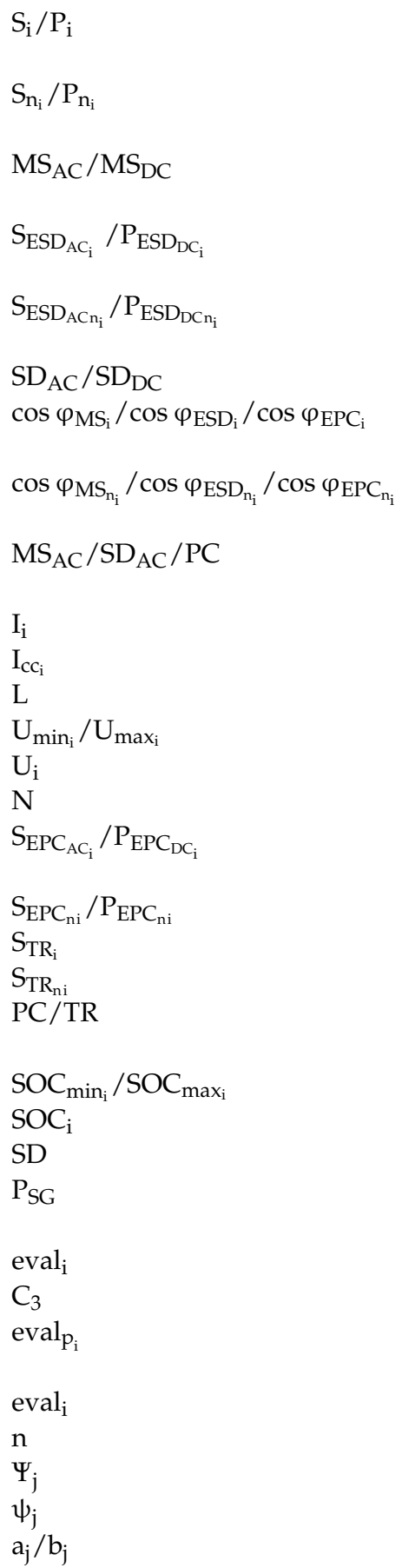

$\mathrm{AFF}_{\mathrm{i}}$

best_eval

$\mathrm{N}_{\mathrm{CL}}$

$\mathrm{N}_{\mathrm{CL}_{\max }} / \mathrm{N}_{\mathrm{CL}_{\min }}$

$\mathrm{AFF}_{\max } / \mathrm{AFF}_{\min }$

$\varepsilon \rightarrow 0$

$\mathrm{P}_{\mathrm{MUT}_{\mathrm{i}}}$

$\mathrm{P}_{\mathrm{MUT}_{\min }} / \mathrm{P}_{\mathrm{MUT}_{\max }}$ apparent/active power generated by $i$ th microsource connected to the AC/DC part of hybrid microgrid nominal apparent/active power of the $i$ th microsource connected to the AC/DC part of hybrid microgrid set of microsources connected to the AC/DC part of hybrid microgrid

apparent/active power measured at the connection point of $i$ th ESD connected to AC/DC part of hybrid microgrid nominal apparent/active power of the $i$ th ESD connected to AC/DC part of hybrid microgrid

set of ESDs connected to AC/DC part of hybrid microgrid power factor of the $i$ th microsource/ESD/EPC connected to the AC part of hybrid microgrid nominal power factor of the $i$ th microsource/ESD/EPC connected to the AC part of hybrid microgrid set of microsources/ESDs/EPCs connected to the AC part of hybrid microgrid

current flow in the $i$ th power line

long-term current capacity of the $i$ th power line set of power lines belonging to the hybrid microgrid minimum/maximum allowable voltage level for $i$ th node voltage measured in $i$ th node

set of nodes belonging to the hybrid microgrid apparent/active power flow through the alternating/direct current circuits of the $i$ th EPC nominal apparent/active power of the $i$ th EPC apparent power flow through the $i$ th transformer nominal apparent power of $i$ th transformer set of EPCs/transformers belonging to the hybrid microgrid

minimum/maximum allowable SOC level of the $i$ th ESD current SOC level of the $i$ th ESD

set of ESDs belonging to the hybrid microgrid active power generated by a synchronous generator acting as a balancing source

evaluation function for $i$ th optimization task

non-negative constant for task 3

evaluation function after taking into account the penalty functions

evaluation function for $i$ th optimization task

number of defined constraints

general form of the penalty function for $j$ th constraint detailed form of the penalty function for $j$ th constraint non-negative coefficient of sensitivity of the penalty function significant for minor/major exceedances of $j$ th constraint

affinity of $i$ th antibody

value of the evaluation function of the antibody encoding the best solution found so far

number of clones of $i$ th antibody from N1 selected antibodies

maximum/minimum number of clones created for a single antibody

maximum / minimum affinity of N1 selected antibodies constant value probability of mutation of $i$ th antibody among the clones created minimum/maximum probability of mutation 


\section{References}

1. Askarzadeh, A. A memory-based genetic algorithm for optimization of power generation in a microgrid. IEEE Trans. Sustain. Energy 2018, 9, 1081-1089. [CrossRef]

2. Rana, M.J.; Zaman, F.; Ray, T.; Sarker, R. Economic-environmental scheduling of community microgrid using evolutionary algorithm. In Proceedings of the 2020 IEEE Symposium series on computational intelligence (SSCI), Canberra, Australia, 1-4 December 2020. [CrossRef]

3. Xu, Y.Q.; Sun, K.Y. Economic optimization of a community-scale integrated energy microgrid based on PSO algorithm. In Proceedings of the 2020 12th IEEE PES Asia-Pacific and Energy Engineering Conference (APPEEC), Nanjing, China, 20-23 September 2020. [CrossRef]

4. Radosavljević, J.; Jevtić, M.; Klimenta, D. Energy and operation management of a microgrid using particle swarm optimization. Eng. Optim. 2016, 48, 811-830. [CrossRef]

5. De Castro, L.N.; Timmis, J.I. Artificial immune systems as a novel soft computing paradigm. Soft Comput. 2003, 7, 526-544. [CrossRef]

6. $\quad$ Lee, T.F.; Hsiao, Y.C.; Wu, H.Y.; Huang, T.L.; Fang, F.M.; Cho, M.Y. Optimization of reactive power compensation and voltage regulation using artificial immune algorithm for radial transmission networks. In Proceedings of the 2007 International Conference on Intelligent Systems Application to Power Systems, ISAP, Toki Messe, Niigata, Japan, 5-8 November 2007. [CrossRef]

7. Pattanaik, J.K.; Basu, M.; Dash, D.P. Optimal Power flow with FACTS devices Rusing artificial immune systems. In Proceedings of the 2017 International Conference on Technological Advancements in Power and Energy, TAP Energy, Kollam, India, 21-23 December 2017. [CrossRef]

8. Gárate, J.I.; Ibarra, E.; Martinez de Alegria, I.; Planas, E.; Andreu, J. AC and DC technology in microgrids: A review. Renew. Sustain. Energy Rev. 2014, 43, 726-749.

9. Hybrid AC/DC Microgrids: A Bridge to Future Energy Distribution System. Available online: http://www.acs.eonerc. rwth-aachen.de/cms/E-ON-ERC-ACS/Forschung/Abgeschlossene-Projekte/ \{\}euwe/HYBRID-AC-DC-MICROGRIDS-ABRIDGE-TO-FUT / ?lidx=1 (accessed on 15 May 2019).

10. Liu, X.; Wang, P.; Loh, P.C. A hybrid AC/DC micro-grid. In Proceedings of the 2010 9th International Power and Energy Conference, IPEC 2010, Singapore, 27-29 October 2010. [CrossRef]

11. Xiao, J.; Nguyen, X.B.; Wang, P.; Huang, J.; Zhou, Q. Implementation of DC/DC converter with high frequency transformer (DHFT) in hybrid AC/DC microgrid. In Proceedings of the 2017 Asian Conference on Energy, Power and Transportation Electrification, ACEPT, Singapore, 24-26 October 2017. [CrossRef]

12. Bandla, K.C.; Prasad Padhy, N. A Multilevel Dual Converter Fed Open End Transformer Configuration for Hybrid AC-DC Microgrid. In Proceedings of the IEEE Power and Energy Society General Meeting, Portland, OR, USA, 5-10 August 2018. [CrossRef]

13. Gu, L.; Jin, K.; Zhu, H.; Wang, C. A single-stage isolated three-phase bidirectional AC/DC converter. In Proceedings of the 2014 IEEE 5th International Symposium on Power Electronics for Distributed Generation Systems, PEDG, Galway, Ireland, 24-27 June 2014. [CrossRef]

14. Lachichi, A.; Junyent-Ferre, A.; Green, T. Power converters design for hybrid LV ac/dc microgrids. In Proceedings of the 2017 6th International Conference on Renewable Energy Research and Applications, ICRERA, San Diego, CA, USA, 5-8 November 2017. [CrossRef]

15. Wu, X.; Wang, Z.; Ding, T.; Li, Z. Hybrid AC/DC Microgrid Planning with Optimal Placement of DC Feeders. Energies 2019, 12, 1751. [CrossRef]

16. Li, J.; Cai, H.; Yang, P.; Wei, W. A Bus-Sectionalized Hybrid AC/DC Microgrid: Concept, Control Paradigm, and Implementation. Energies 2021, 14, 3508. [CrossRef]

17. Nasir, M.; Khan, H.A. Solar photovoltaic integrated building scale hybrid AC/DC microgrid. In Proceedings of the 5th IET International Conference on Renewable Power Generation (RPG), London, UK, 21-23 September 2016. [CrossRef]

18. Ma, T.; Cintuglu, M.H.; Mohammed, O. Control of hybrid AC/DC microgrid involving energy storage, renewable energy and pulsem loads. In Proceedings of the 2015 IEEE Industry Applications Society Annual Meeting IAS 2015, Addison, OR, USA, 18-22 October 2015. [CrossRef]

19. Vigneysh, T.; Kumarappan, N.; Arulraj, R. Operation and control of wind/fuel cell based hybrid microgrid in grid connected mode. In Proceedings of the 2013 IEEE International Multi-Conference on Automation, Computing, Control, Communication and Compressed Sensing, (iMac4s), Kattayam, India, 22-23 March 2013. [CrossRef]

20. Debela, T.; Bhattacharya, A. Design and analysis of a DC/AC microgrid with centralized battery energy storage system. In Proceedings of the IECON 2017-43rd Annual Conference of the IEEE Industrial Electronics Society, Beijing, China, 29 October-1 November 2017. [CrossRef]

21. Rahman, M.S.; Hossain, M.J.; Lu, J. Utilization of parked EV-ESS for power management in a grid-tied hybrid AC/DC microgrid. In Proceedings of the Ausralasian Universities Power Engineering Conference, AUPEC 2015, Wollongong, Australia, 27-30 September 2015. [CrossRef]

22. Rahman, M.S.; Hossain, M.J.; Rafi FH, M.; Lu, J. EV charging in a commercial hybrid AC/DC microgrid: Configuration, control and impact analysis. In Proceedings of the 2016 Australasian Universities Power Engineering Conference, AUPEC 2016, Brisbane, Australia, 25-28 September 2016. [CrossRef] 
23. Ouramdane, O.; Elbouchikhi, E.; Amirat, Y.; Sedgh Gooya, E. Optimal Sizing and Energy Management of Microgrids with Vehicle-to-Grid Technology: A Critical Review and Future Trends. Energies 2021, 14, 4166. [CrossRef]

24. Kaushik, R.A.; Pindoriya, N.M. A hybrid AC-DC microgrid: Opportunities \& key issues in implementation. In Proceedings of the IEEE International Conference on Green Computing, Communication and Electrical Engineering, ICGCCEE 2014, Coimbatore, India, 6-8 March 2014. [CrossRef]

25. Unamuno, E.; Barrena, J.A. Hybrid ac/dc microgrids-Part I: Review and classification of topologies. Renew. Sustain. Energy Rev. 2015, 52, 1251-1259. [CrossRef]

26. Mirsaeidi, S.; Dong, X.; Said, D.M. Towards hybrid AC/DC microgrids: Critical analysis and classification of protection strategies. Renew. Sustain. Energy Rev. 2018, 90, 97-103. [CrossRef]

27. Mirsaeidi, S.; Dong, X.; Shi, S.; Tzelepis, D. Challenges, advances and future directions in protection of hybrid AC/DC microgrids. IET Renew. Power Gener. 2017, 11, 1495-1502. [CrossRef]

28. Rahman Fahim, S.; Sarker, S.K.; Muyeen, S.M.; Sheikh, M.R.I.; Das, S.K. Microgrid Fault Detection and Classification: Machine Learning Based Approach, Comparison, and Reviews. Energies 2020, 13, 3460. [CrossRef]

29. Ambia, M.N.; Al-Durra, A.; Muyeen, S.M. Centralized power control strategy for AC-DC hybrid micro-grid system using multi-converter scheme. In Proceedings of the IECON 2011-37th Annual Conference of the IEEE Industrial Electronics Society, Melbourne, Australia, 7-10 November 2011. [CrossRef]

30. Aryani, D.R.; Song, H. Coordination Control Strategy for AC/DC Hybrid Microgrids in Stand-Alone Mode. Energies 2016, 9, 469. [CrossRef]

31. PowerFactory v.15.2 Manual (DIgSILENT Technical Documentation). Available online: http://www.digsilent.de (accessed on 13 September 2019).

32. Hoke, A.; Maksimović, D. Active power control of photovoltaic power systems. In Proceedings of the 2013 1st IEEE Conference on Technologies for Sustainability, SusTech, Portland, OR, USA, 1-2 August 2013. [CrossRef]

33. Khosa, F.K.; Zia, M.F.; Bhatti, A.A. Genetic algorithm based optimization of economic load dispatch constrained by stochastic wind power. In Proceedings of the ICOSST 2015 International Conference on Open Source Systems and Technologies, Lahore, Pakistan, 17-19 December 2015. [CrossRef]

34. Naimi, D.; Ahmed, S.; Bouktir, T. An efficient optimization method based on genetic algorithm applied to reduce greenhouse gases in power system. In Proceedings of the 2013 International Conference on Control, Decision and Information Technologies, CoDIT, Hammamet, Tunisia, 6-8 May 2013. [CrossRef]

35. Babaei, A.; Razavi, S.; Kamali, S.; Gholami, A. Performance improvement of power system stabilizer be genetic algorithm for one machine infinite bus system. In Proceedings of the 2007 42nd International Universities Power Engineering Conference, Brighton, UK, 4-6 September 2007. [CrossRef]

36. Liang, H.; Gu, X.; Zhao, D. Optimization of system partitioning schemes for power system black-start restoration based on genetic algorithms. In Proceedings of the 2010 Asia-Pacific Power and Energy Engineering Conference, APPEEC, Chengdu, China, 28-31 March 2010. [CrossRef]

37. Atia, R.; Yamada, N. Optimization of a PV-wind-diesel system using a hybrid genetic algorithm. In Proceedings of the 2012 IEEE Electrical Power and Energy Conference, London, ON, Canada, 10-12 October 2012. [CrossRef] 